\title{
Gender unemployment gaps in the EU: blame the family
}

\author{
Alena Bičáková
}

Correspondence:

alena.bicakova@cerge-ei.cz CERGE-El, a joint workplace of Charles University and the Economics Institute of the Czech Academy of Sciences, Politickych veznu 7, 11121 Prague, Czech Republic

\begin{abstract}
There are considerable differences in gender unemployment gaps across the EU. We use labor force survey data on 21 countries to perform a series of data decompositions and show that the cross-country variation in gender unemployment gaps is primarily driven by the differences in female labor force participation behavior after childbirth, namely, the family leave duration and the subsequent attachment of women to the labor force. Further, in countries where a high share of women permanently withdraw from the labor force after childbirth, the size of gender differences in unemployment strongly correlates with the Eurobarometer measure of perceived overall gender discrimination. Our findings suggest that family leave policies and institutions that facilitate the leave to work transition and the work-family balance are crucial to tackle the gender differences in unemployment in countries where the female unemployment rate exceeds that of men.
\end{abstract}

Keywords: Gender unemployment gap, Family leave, Gender discrimination JEL Classification: J13, J21, J70

\section{Introduction}

The rise in educational attainment and labor force participation of women has contributed to the convergence in gender gaps in various labor market outcomes over the last decades. Yet, gender differences in the labor market still persist, and their size varies considerably across countries (OECD 2002; 2008). Research looking for an explanation of these cross-country differences has predominantly focused on gender wage gaps: see Altonji and Blank (1999) for a review and subsequent studies such as Blau and Kahn (2003), Weichselbaumer and Winter-Ebmer (2005), or Weichselbaumer and Winter-Ebmer (2007). There are papers that discuss gender employment gaps (Algan and Cahuc 2007; Bertola et al. 2007); ${ }^{1}$ however, only one study, Azmat et al. (2006)hereinafter AGM, has tried to systematically account for the cross-country variation in gender differences in unemployment. ${ }^{2}$

The focus of this paper is the variation in gender unemployment gaps across the European Union. While our findings are in line with the general conclusions of AGM that human capital, family, and labor market institutions, as well as prejudice, are important to explain the gender differences in unemployment across countries, this paper offers both a more parsimonious and a more specific account of the substantial cross-country variation in gender unemployment gaps in 21 countries of the European Union (including the

(c) The Author(s). 2016 Open Access This article is distributed under the terms of the Creative Commons Attribution 4.0 International License (http://creativecommons.org/licenses/by/4.0/), which permits unrestricted use, distribution, and reproduction in any medium, provided you give appropriate credit to the original author(s) and the source, provide a link to the Creative Commons license, and indicate if changes were made. 
New-EU member states) a decade later. ${ }^{3}$ We show that gender unemployment gaps across the EU are primarily driven by female labor force participation after childbirth, namely, the family leave duration and the subsequent attachment of women to the labor force. Further, in countries, where a high share of women permanently withdraw from the labor force after childbirth, the size of gender differences in unemployment strongly correlates with the Eurobarometer measure of perceived overall gender discrimination.

How large are gender unemployment gaps? While no major gender differences in unemployment rates have been observed in Anglo-Saxon countries since the $1990 \mathrm{~s},{ }^{4}$ gender differences between female and male unemployment rates exceed two percentage points (p.p.) in more than one third of the countries of the European Union and many of them do not show any sign of convergence a decade later. In 2007, gender unemployment gaps across the EU ranged from a small negative gender unemployment gap (i.e., in favor of women) in Ireland and no gaps in the three Baltic States, Finland, Germany, Hungary, Luxembourg, and the UK, to gender unemployment gaps exceeding 3 p.p. in Greece, Italy, Portugal, Spain, the Czech Republic, and Slovakia. When we look at the average gender unemployment gaps over 2003-2007 to smooth out the business-cycle effects, as plotted in Fig. 1, the cross-country variation and countries' ranking remain almost the same, with the average gender unemployment gaps ranging from about -1 p.p. to 8 p.p. ${ }^{5}$

The Great Recession that followed the 2008 Financial Crisis hit primarily the maledominated sectors and helped reduce the observed gender unemployment gaps in some of the countries (Hoynes et al. 2012). The size of the impact of the Great Recession, driven primarily by the country's industrial structure, was unrelated to the long-term gender inequalities in the labor markets. The high unemployment rates among men have declined in the years following the Recession, as the male-dominated sectors started

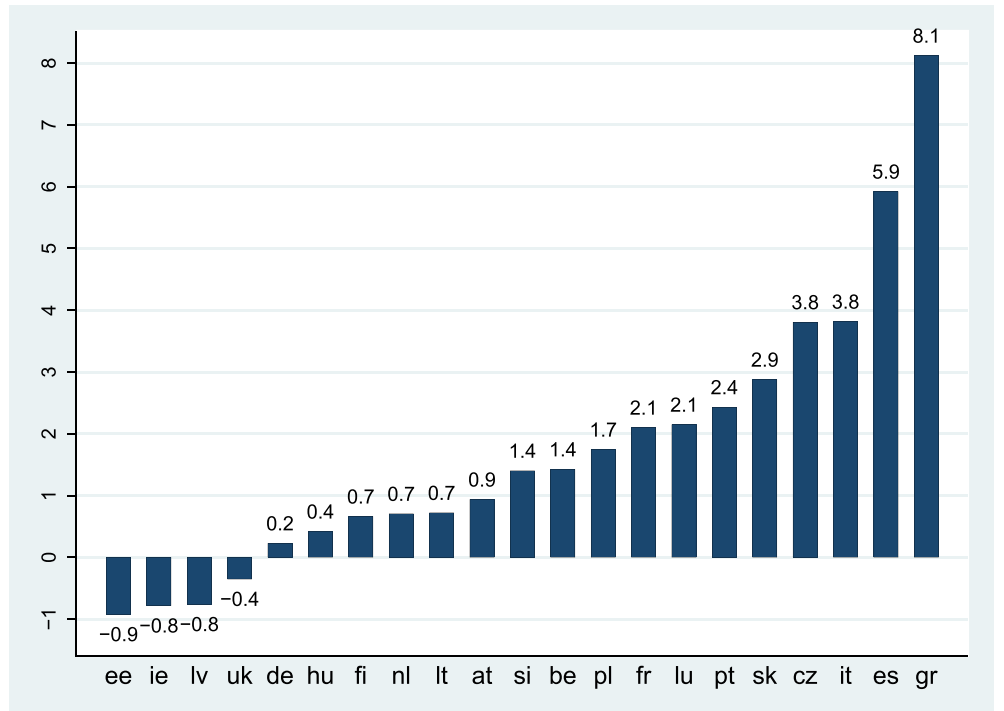

Fig. 1 Gender unemployment gaps in 2003-2007 (5-year average). Note: EU LFS data, sample of prime age individuals (25-54 years old). Standard ILO definition of unemployment. Own calculations. Weighted by sampling weights. Gender unemployment gaps are measured in percentage points as the differences between female and male unemployment rates. Unemployment rate is defined as the share of unemployed in the labor force. Individuals on family leave are universally coded as out of the labor force. The coefficient of variation is 1.3 
to recover. Various austerity measures induced by the Recession, on the other hand, negatively affected the female-dominated public sectors, resulting in the rise of female unemployment rates. These EU-wide trends led to a gradual increase in gender unemployment gaps towards their pre-Recession levels (ILO 2016). While the differences between female and male unemployment rates were (still) much smaller in the majority of the countries in 2013 relative to 2007, the cross-country variation in gender unemployment gaps 5 years after the Crisis remained surprisingly similar to that in 2007, as Fig. 2 attests. ${ }^{6}$ This paper focuses on the long-term variation in the gender unemployment gaps across the EU driven by structural rather than cyclical factors. Using the 5 years (2003-2007) immediately preceding the Great Recession allows us to both smooth the business-cycle effects on gender unemployment gaps over a relatively stable period and, given the persistence in countries' ranking, be equally informative about the post-Recession cross-country variation in gender unemployment gaps in 2013 and onwards.

The aim of this paper is to explain the cross-country variation in gender unemployment gaps, as documented in Fig. 1, using 21 national labor force surveys standardized into the European Union Labor Force Survey dataset. ${ }^{7}$ In line with the previous literature, we use the International Labor Organization (ILO) definition of unemployment and define gender unemployment gap as the difference between female and male ILO unemployment rates. In order to ensure a comparable size of the potential labor force across countries, we avoid cross-country differences at the beginning and end of a labor market career (which might be due to different educational systems and retirement schemes) by limiting our analysis to prime age individuals, i.e., those between 25 and 54 years of age. ${ }^{8}$

Using a series of data decompositions, we conclude that the cross-country variation in gender unemployment gaps is primarily driven by the differences in female labor force

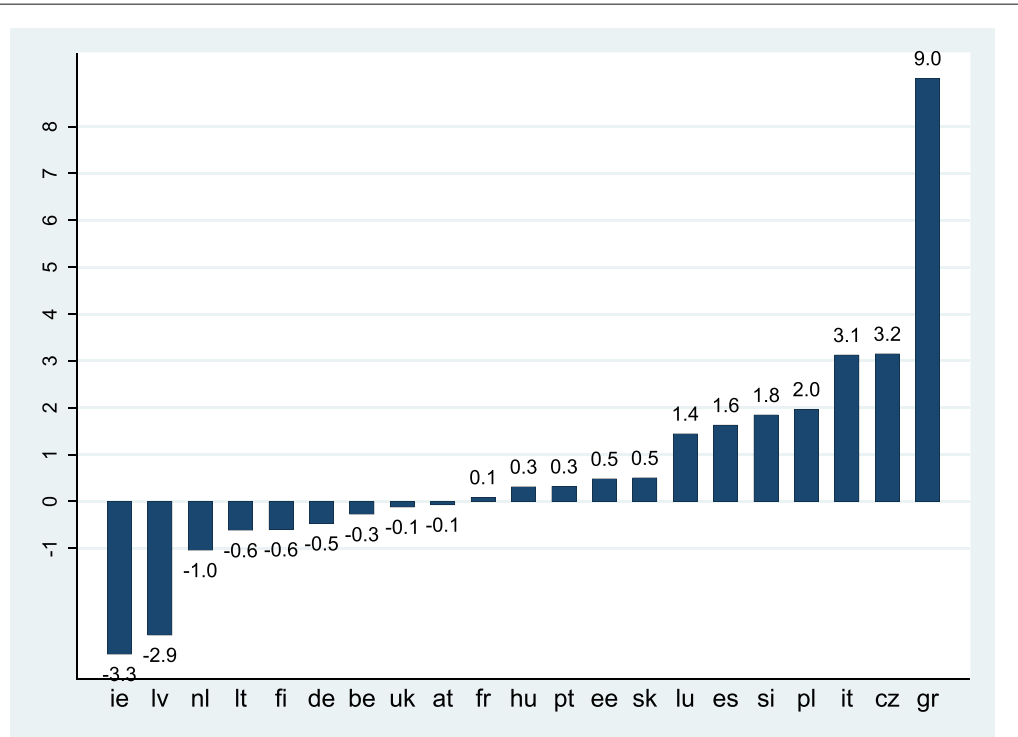

Fig. 2 Gender unemployment gaps in 2013. Note: EU LFS data, sample of prime age individuals (25-54 years old). Standard ILO definition of unemployment. Own calculations. Weighted by sampling weights. Gender unemployment gaps are measured in percentage points as the differences between female and male unemployment rates. Unemployment rate is defined as the share of unemployed in the labor force. Individuals on family leave are universally coded as out of the labor force 
participation behavior after childbirth, namely, the family leave duration and the subsequent attachment of women to the labor force. Our conclusion is based on the following findings:

A flexible version of the Oaxaca-Blinder decomposition shows that gender differences in age and education explain only $23 \%$ of the cross-country variation in gender unemployment gaps. The presence of children, on the other hand, is the major determinant of the gender differences in unemployment in the EU countries. While gender unemployment gaps among individuals with children younger than 15 in the family exceed 2.5 p.p. in 16 out of the 21 countries, women and men without children are almost equally likely to be unemployed in 18 of the countries. Gender unemployment gaps are always the highest among individuals with children between 0 and 4, driven by a high unemployment rate among women. We show that the rise in the female unemployment rate after childbirth is to a large extent driven mechanically by the withdrawal of women from employment into family leave and the negative selection of women into the labor force at that period. When women return from their family leave, the gender unemployment gaps in the majority of the countries are still substantial and reflect the true rise in female joblessness relative to that of men. However, in at least two thirds of the countries, gender unemployment gaps diminish as the youngest child becomes older than 10.

Based on the labor force participation behavior after childbirth, we distinguish two types of countries: the temporary leave countries, where women take family leaves of various lengths after childbirth and then typically return to the labor force, and the permanent withdrawal countries, where the shape of the participation profiles suggests that the majority of women who leave the labor force after childbirth never return. ${ }^{9}$ The eight permanent withdrawal countries include Ireland, the Benelux, and the Mediterranean countries except for France; the remaining 13 countries belong to the temporary leave countries.

Two facts arise as crucial for the observed cross-country variation in gender unemployment gaps: the existence and the duration of career breaks after childbirth (in temporary leave countries) and the overall position of women at the labor market and their attachment to the labor force (in permanent withdrawal countries). In line with these findings, it turns out that the observed behavioral patterns driving the cross-country variation in gender unemployment gaps can be "explained" to a great degree by a single factor, a different one for the two types of countries: by the statutory duration of paid family leave in the temporary leave countries and by the Eurobarometer measure of perceived prevalence of gender discrimination in the permanent withdrawal countries. We further demonstrate the importance of paid family leave for the variation in gender unemployment gaps across the EU using country-level panel data over 25 years that allow us to exploit institutional changes in the family leave policies. The regression of gender unemployment gaps on the duration of paid family leave, with country and year fixed effects, implies that increasing the duration of paid family leave by 1 year ( 54 weeks) increases the gender unemployment gap by 0.865 p.p.

Our findings suggest that family leave policies and institutions affecting mothers' transition from leave to work and facilitating the subsequent family-work balance will be more effective to tackle the observed gender unemployment gaps (in favor of men) than any other active labor market policies targeted at women in general. 
The paper is organized as follows: In the next section, we ask to what extent gender differences in human capital explain the observed gender unemployment gaps. The third section explores gender differences in unemployment and labor force participation behavior across different stages of family life. In the fourth section, we focus on the relationship between female labor force participation and gender unemployment gaps. The fifth section summarizes the main findings from the decompositions, presents the proposed account of the cross-country variation in gender unemployment gaps, and discusses the underlying institutions and social norms. The sixth section concludes.

\section{Gender differences in human capital}

The risk of being unemployed decreases with the level of human capital (Mincer 1993). In this section, we ask to what extent gender differences in human capital can explain the observed gender unemployment gaps and their cross-country variation. We separately focus on the level of human capital with which individuals enter the labor market (premarket human capital $)^{10}$ and on the human capital accumulated while in the labor market (market human capital). ${ }^{11}$

\subsection{Pre-market human capital}

Unemployment rates concentrate among the least-educated individuals and substantially decrease with every education level almost universally across the OECD countries (OECD 2008). We measure pre-market human capital by the level of education within a given age cohort. This allows us to compare women and men who entered the labor market with the same level of human capital at the same time and have had the same number of years available to accumulate market human capital until today. ${ }^{12}$ In order to determine how much of the observed gender unemployment gaps can be explained by gender differences in pre-market human capital, we use a flexible version of the Oaxaca-Blinder decomposition based on a simplified version of the methodology from Nopo (2008), where the simplification results from the fact that we condition only on discrete explanatory variables.

Consider $J$ cells based on discrete versions of individual characteristics $X$ (in our case, these are 18 cells constructed on the basis of three levels of education and six age categories). ${ }^{13}$ The overall gender unemployment gap $U_{\text {gap }}$ defined as the difference between the female $u^{F}$ and male $u^{M}$ unemployment rate can be expressed in terms of the $J$ groups as follows:

$$
U_{\text {gap }}=u^{F}-u^{M}=\sum_{j} w_{j}^{F} u_{j}^{F}-\sum_{j} w_{j}^{M} u_{j}^{M},
$$

where $u_{j}^{G}$ is the unemployment rate in cell $j$ for gender $G$ and $w_{j}^{G}$ is the share of individuals of gender $G$ from cell $j$ in the labor force of gender $G$. Adding and subtracting terms for the overall gender-neutral unemployment rates weighted by the gender-specific weights, $\sum_{j} w_{j}^{F} u_{j}$ and $\sum_{j} w_{j}^{M} u_{j}$, we get

$$
U_{\text {gap }}=\underbrace{\sum_{j} w_{j}^{F}\left(u_{j}^{F}-u_{j}\right)}_{A}+\underbrace{\sum_{j} w_{j}^{M}\left(u_{j}-u_{j}^{M}\right)}_{B}+\underbrace{\sum_{j}\left(w_{j}^{F}-w_{j}^{M}\right) u_{j}}_{C} .
$$

While $A$ and $B$ reflect the part of the unemployment gap that is due to gender differences in unemployment within the respective cells, $C$ captures the gender differences in 
the distribution of individuals across the cells. In terms of the traditional terminology of gender gap decompositions, $C$ is the part of the gender unemployment gap that is driven by differences in observed characteristics and $A+B$ is the part of the gap that remains unexplained. Note that $A+B$ measures the counterfactual-the hypothetical gender difference in unemployment under pre-market human capital equality. We present these "pre-market human capital-adjusted" gender unemployment gaps in Fig. 3, next to the unadjusted ones, with countries ordered by the unadjusted gaps as in Fig. 1. Both gender unemployment gap measures are constructed annually but are then averaged over the studied period 2003-2007 in order to smooth out any cyclical factors at the aggregate level.

Figure 3 suggests that in a majority of the countries, the gender unemployment gap under pre-market human capital equality exceeds the observed gender unemployment gap, which implies that women have a more favorable distribution of pre-market human capital than men. This is not surprising, given the well-documented universal rise in female education over the last decades and the fact that women are on average more educated than men in many developed countries (OECD 2002).

The counterfactual gap is lower than the unadjusted gap in only five countries, revealing that part of the observed gender unemployment gap (35\% in Austria, 29\% in Slovakia, 17\% in the Czech Republic, 3\% in Greece, and 1.5\% in Luxembourg) is due to better pre-market human capital characteristics of men when compared to women. ${ }^{14}$ To summarize, gender differences in pre-market human capital explain only $23 \%$ of the observed cross-country variation in gender unemployment gaps. ${ }^{15}$ Moreover, in a majority of the countries, the observed gender unemployment gaps actually underestimate the true gender differences in unemployment.

\subsection{Market human capital and the role of children}

Gender differences in market human capital accumulation can be driven by various factors, yet there is one which makes women's and men's career paths always unequal:

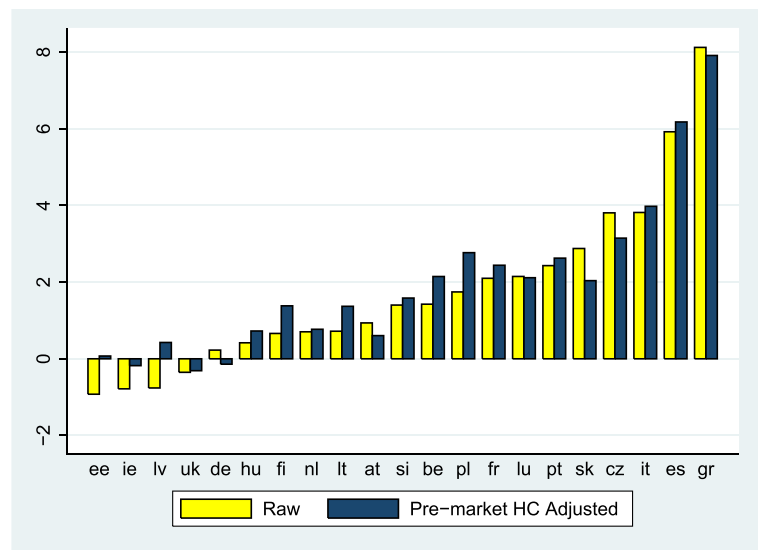

Fig. 3 Raw and pre-market HC-adjusted gender unemployment gaps. Note: Raw gaps are 5-year averages of gender unemployment gaps among prime age individuals over 2003-2007, constructed using sampling weights. The corresponding hypothetical gender unemployment gaps under pre-market human capital equality are constructed based on a flexible version of the Oaxaca-Blinder decomposition using age and education groups as individual characteristics. The pre-market human capital-adjusted unemployment gaps are 5-year averages of the constructed hypothetical gaps, using sampling weights, over 2003-2007. Countries are ordered by the raw (unadjusted) gaps. Gaps are in p.p 
childbirth. Following previous research which has faced similar data limitations, we use the presence of children as a proxy for gender differences in market human capital accumulation. Figure 4 reveals that the effect of children on gender differences in unemployment is indeed enormous. The two panels of Fig. 4 plot male unemployment rates against female unemployment rates in the 21 countries separately for individuals with and without children younger than 15 present in the household.

In the left panel, a vast majority of the points are around or to the left of the $45^{\circ}$ line, suggesting that in most of the countries there are no gender unemployment gaps in favor of men among individuals without children. The only exceptions are Greece, Italy, and Spain, where the female unemployment rate substantially exceeds that of the male even among the individuals without children. The right panel, where all data points are to the right of the $45^{\circ}$ line, reveals non-negligible gender unemployment gaps in favor of men among individuals with children in almost all the countries studied. Finally, comparing the two panels, we see that moving from left to right, the country-specific data points move east more than south, indicating that gender unemployment gaps among individuals with children are driven more by the above-average female unemployment rates than the below-average male unemployment rates when compared to individuals without children.

Three conclusions can be derived from Fig. 4: First, any analysis of gender unemployment gaps should primarily concentrate on the presence of children as the main factor which makes female and male unemployment rates diverge. Second, gender unemployment gaps should be discussed separately for individuals with children and without children present in the household. Third, the focus of the research should be on the above-average unemployment rates of women with children, when compared to men and

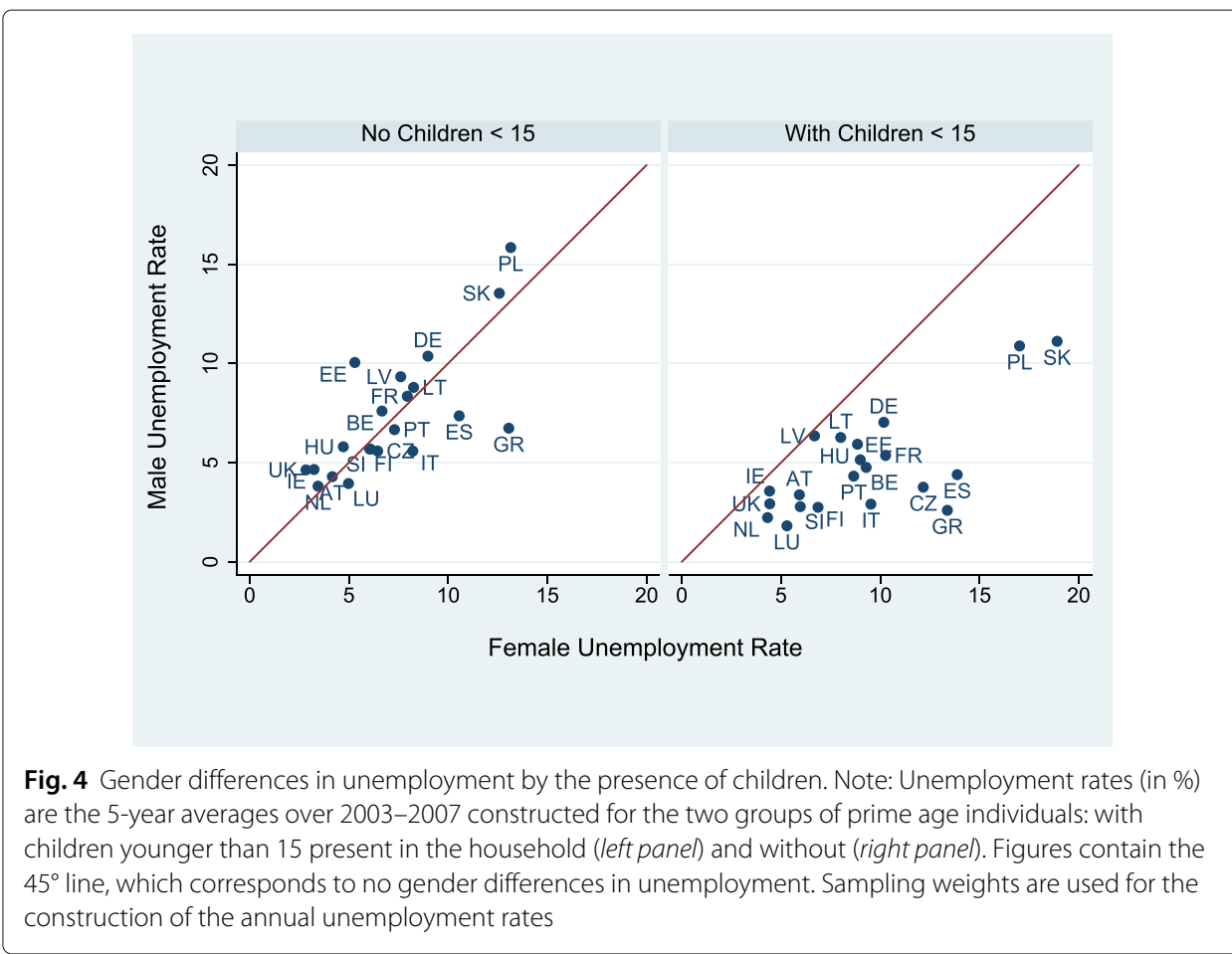


to women without children, as that seems to be the main source of the observed gender differences in unemployment.

\section{Gender gaps across five stages of family life}

We have so far interpreted the presence of children as an indicator of women's past career interruptions that lead to gender differences in market human capital. The presence of young children may also increase their mothers' risk of unemployment by reducing their work effort when they are working or their job search effort when they are unemployed (Becker 1985). In order to understand better how children of various ages affect gender differences in unemployment, we next disaggregate our sample of prime age individuals by the individual's age, fertility, and the age of children. In particular, we divide individuals in our sample into the following five stages of family life: individuals younger than 40 with no children below 15 (Group 0); individuals with the youngest child younger than 5 (Group 1); with the youngest child younger than 10 but at least 5 years old (Group 2); with the youngest child younger than 15 but at least 10 years old (Group 3); and individuals older than 40 with no children younger than 15 present in the family (Group 4). Individuals who have children at some point in their life go through all five stages of family life; individuals who have no children move directly from Group 0 to Group 4. While Groups 1-3 represent individuals with children at three different stages since the last childbirth, Group 0 captures childless individuals who may or may not have children in the future and Group 4 comprises a mixture of individuals above 40 who have never had children or whose children are older than $15 .^{16}$

As we neither have panel data with individual histories nor can we construct a pseudopanel based on cohorts because the time span of the data is too short and age information is only available in 5-year age bands, we construct the five stages of family life from crosssectional surveys based on age, fertility, and the age of the youngest child. The shape of the presented profiles may therefore reflect the within-cohort evolution as well as changes between cohorts. Note, however, that the fact that the three inner parts of the profiles are constructed based on the age of the youngest child rather than the age of the mother brings additional variation into the within-cohort and across-cohort divides. We believe that profiles based on an individual's age and the age of the youngest child are preferable to cohort-based profiles for our present question, as aggregate economic conditions are more likely to affect the shape (and not the level) of the latter than of the former. Moreover, all outcomes, constructed from the annual cross-sectional surveys, are measured as 5-year averages over 2003-2007 to smooth out business-cycle effects.

\subsection{Unemployment profiles: gaps, rates, and shares}

Figure 5 shows the evolution of gender unemployment gaps across the five stages of family life as defined above. The typical gender unemployment gap profile is hump-shaped, suggesting that gender unemployment gaps are concentrated almost solely during the first 10 years from the last child's birth. In over two thirds of the countries, gender differences in the unemployment rate reach their maximum during the first stage following childbirth (Group 1) and then gradually decrease as children get older (Groups 2 and 3). In 15 of the 21 countries, gender differences in unemployment rates are either smaller than 1 p.p. or in favor of women among the childless and those with children 15 or older (Groups 0 and 4). ${ }^{17}$ Finally, it is only in Greece, Italy, Spain, Slovenia, and Finland that women have 


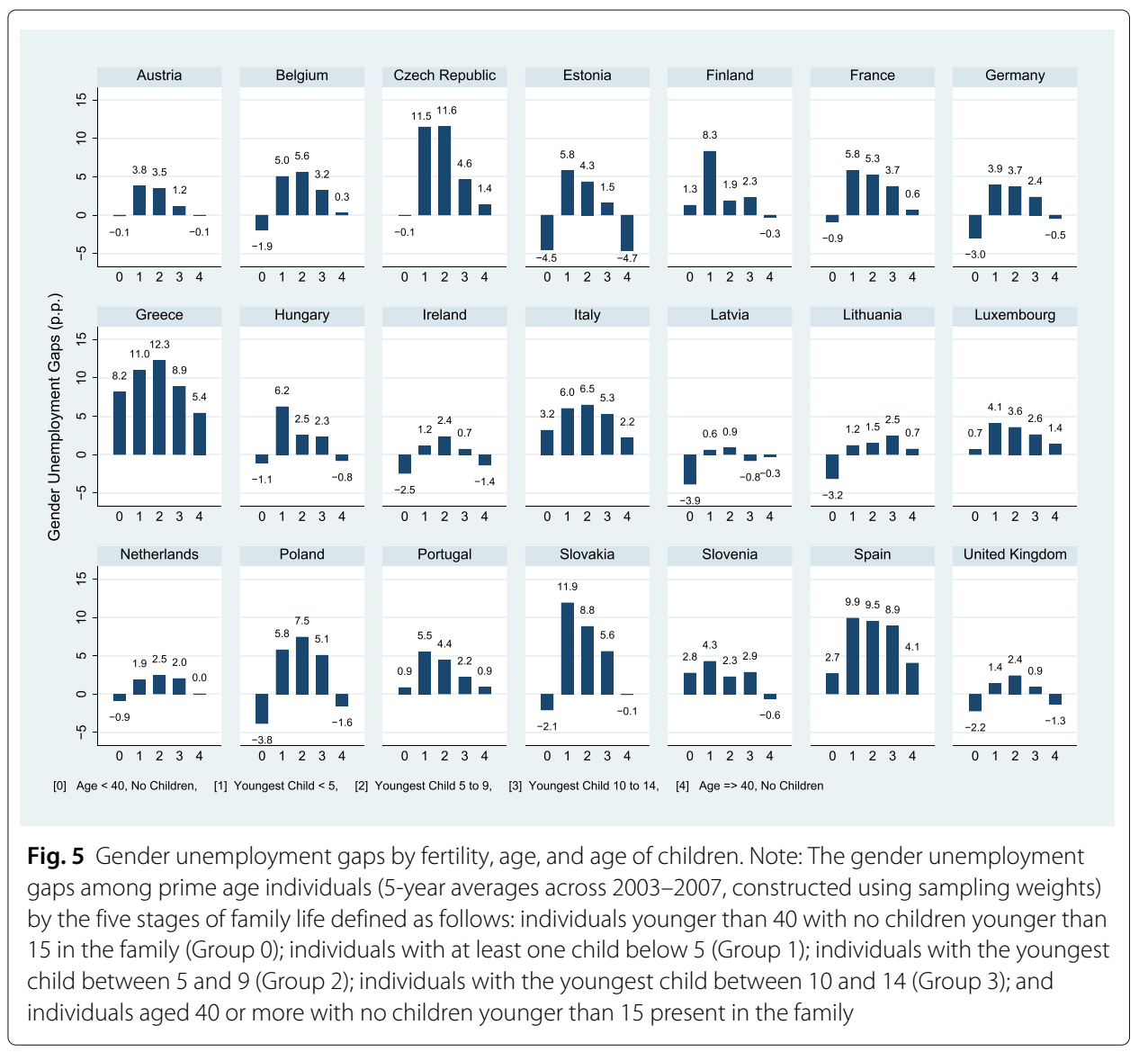

a substantially higher risk of being unemployed already when they are young and before they start having children (Group 0).

Figure 6 confirms that it is the evolution of the female unemployment rate rather than the male unemployment rate that contributes most to the documented gender unemployment gap profiles over the five stages of family life. Similar to gender unemployment gaps, female unemployment rates are also hump-shaped across the family life with the highest values at the two stages following childbirth. ${ }^{18}$ Male unemployment rate profiles, on the other hand, are almost always much flatter than those of women. While we can detect-in particular among some of the Mediterranean countries and in Poland-a mirror image of the hump shape in the unemployment rates of women in the shape of male unemployment rate profiles, suggesting that men with children in the household have lower unemployment rates than men without, it is much less pronounced. ${ }^{19}$ While this so-called family gap in the male unemployment rate somewhat contributes to the observed gender unemployment gaps, its impact is almost always of a second-order importance relative to the corresponding "family gap" in female unemployment rates.

To disentangle the changes in unemployment rates due to changes in the number of unemployed from those due to changes in the size of the labor force, ${ }^{20}$ Fig. 6 also shows the evolution of the gender-specific shares of the unemployed in the respective population sub-groups. We see that while the male unemployment rate and the share of the unemployed among men are almost indistinguishable across the five stages of family life, the female unemployment rate and the share of the unemployed among women 


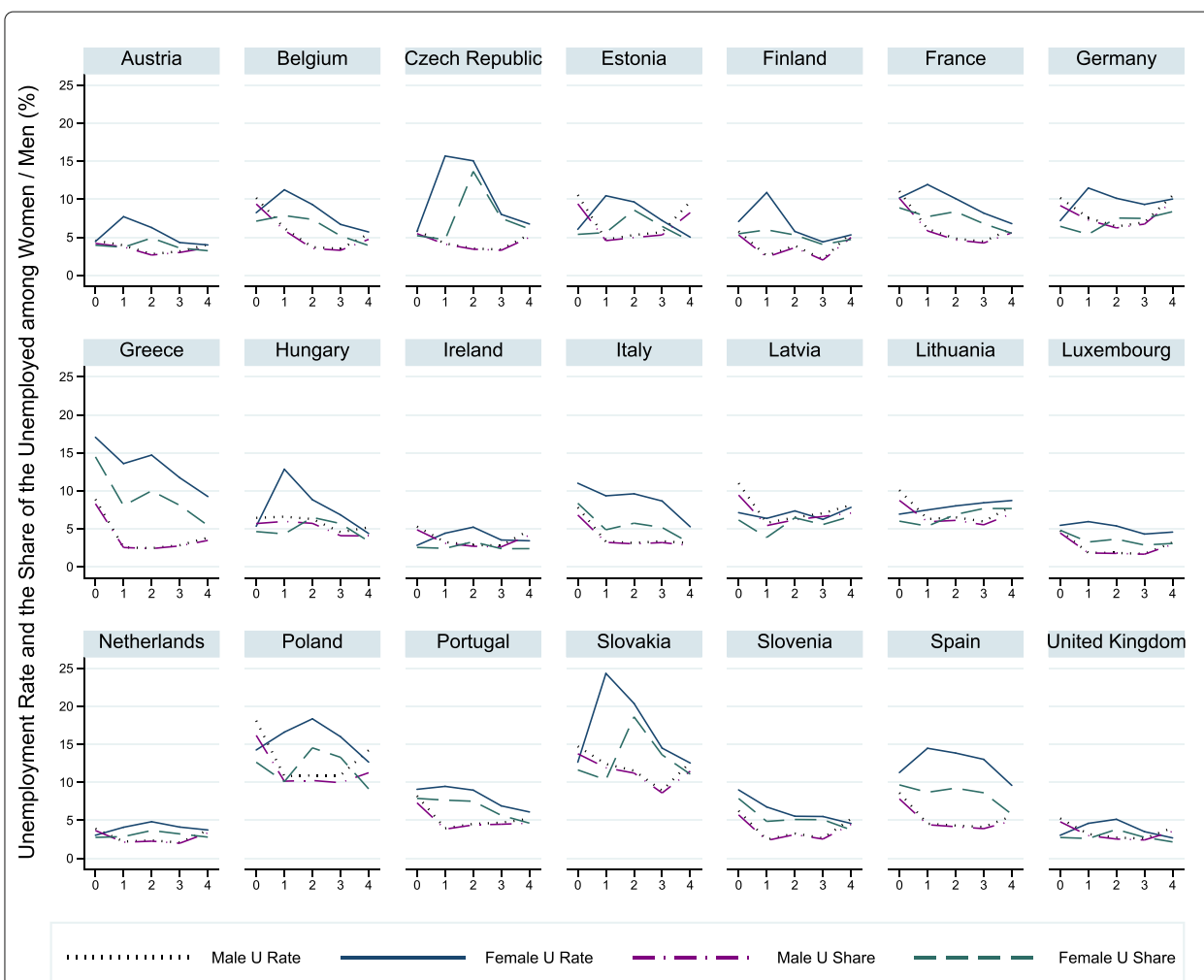

[0] Age $<40$, No Child, [1] Child $<5$, [2] Child 5 to 9, [3] Child 10 to 14, [4] Age $=>40$, No Child

Fig. 6 Unemployment rates and shares of the unemployed across family life. Note: $U$ Rate is the unemployment rate, $U$ Share is the share of unemployed in the population of the respective sub-group of prime age individuals. Both measures are expressed in percentages and represent 5-year averages over 2003-2007 (underlying annual figures are constructed using sampling weights). The five stages of family life are defined as follows: individuals younger than 40 with no children younger than 15 in the family (Group 0); individuals with at least one child below 5 (Group 1); individuals with the youngest child between 5 and 9 (Group 2); individuals with the youngest child between 10 and 14 (Group 3); and individuals aged 40 or more with no children younger than 15 present in the family

often diverge. Prior to discussing the differences between the two alternative measures of unemployment, we first complete the picture by exploring the gender-specific labor force participation behavior across the five stages of family life.

\subsection{Labor force participation profiles}

Figure 7 suggests that the labor force participation behavior of men does not differ substantially across countries: the male participation rate remains stable across the five stages of family life and is always above that of women. ${ }^{21}$ On the other hand, the female labor force participation varies substantially both across different stages of family life as well as across countries. Based on the shape of the labor force participation profiles of women, we can identify two types of countries, which we shall call the temporary leave countries and the permanent withdrawal countries.

In the temporary leave countries, presented in the top half of Fig. 7, female participation rates are (with the exception of Finland) the same as those of men at the first stage of family life, before the potential family formation (Group 0 ). It is only at the second stage (Group 1) that gender labor force participation gaps open up, as women leave the labor 


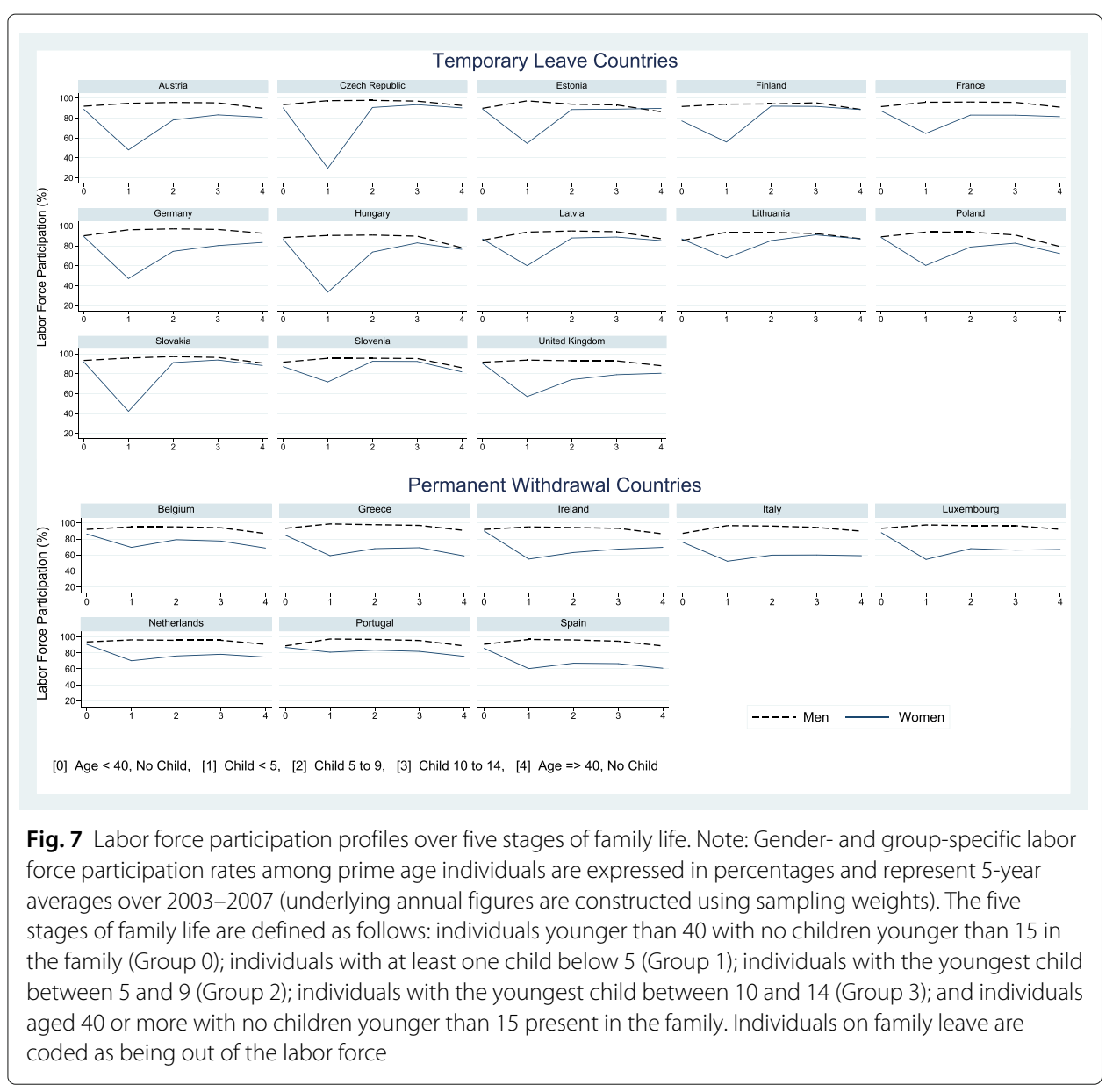

force due to childbirth. After the family-related career interruption, women start returning to the labor force again as children get older (Group 2 or 3). At the last stage of family life (Group 4), the female labor force participation rate converges back to the male participation rate and the gender participation gap either disappears or substantially narrows relative to the stages directly following childbirth. In the permanent withdrawal countries, presented in the bottom half of Fig. 7, gender participation gaps, which are in some of the countries present already before the family formation (Group 0), also widen at the second stage as women leave the labor force after childbirth (Group 1), but in contrast to the temporary leave countries, they persist over the rest of family life. There are 13 temporary leave countries and 8 permanent withdrawal countries. The latter include Ireland, the Benelux countries, and the Mediterranean countries except for France.

The classification of countries into the two groups meets the following formal definition: a country is classified as a permanent withdrawal country if, among all women who dropped out of the labor force after childbirth, the share of women who return to the labor force by the fourth stage of family life (Group 3) is lower than $50 \%{ }^{22}$ There are three temporary leave countries (France, Germany, and the UK) where-as suggested by the participation profiles - a non-negligible number of women stay out of the labor force until the last stage of family life. However, their share in the total number of women who left the labor force after childbirth is small relative to those who return to the labor force again. 
There are also several permanent withdrawal countries, such as Ireland or the Netherlands, where some women return to the labor force in Group 2 or later, yet the majority of women who leave the labor force do not come back.

The construction of the labor force participation profiles requires two clarifications. First, as age is only available in 5-year bands in our data, the drop in female labor force participation moving from Group 0 to Group 1 reflects the share of women who take family leaves after childbirth as well as the average duration of the family leaves taken. Our definitions of Groups 1-3 are based on the age of the youngest child so that the length of the family leave, as implied by the depth of the drop in participation, measures the average duration of the career interruption due to one childbirth.

Second, as most of the permanent withdrawal countries have experienced a substantial rise in female labor force participation over the last several decades, the comparison of female participation rates at the first and the last stages of family life may reflect intercohort changes rather than individual behavior. ${ }^{23}$ While we cannot disentangle the two by constructing full cohort-based profiles, the data permit us to conduct a simplified cohort analysis which suggests that the shape of the profiles represent within-cohort behavior and that inter-cohort changes in female labor force participation only shifts the profiles upwards. ${ }^{24}$ This is also supported by individual-level evidence based on the previous year status reported in EU LFS data, suggesting that the share of currently inactive women out of those who were inactive due to domestic tasks or family responsibilities a year ago exceeds $90 \%$ in the permanent withdrawal countries but ranges between 60 and $85 \%$ among the temporary leave countries.

\section{Female participation and unemployment gaps}

The shape of the female participation profiles corresponds to the differences in the evolution of female unemployment rates and the share of the unemployed among women, as presented in Fig. 6. In this section, we first outline the mechanisms that underpin the relationship between female labor force participation behavior and gender unemployment gaps and then discuss their presence in the data. As male unemployment rates are stable across the five stages of family life and do not vary much across countries, we limit our account of the variation in gender unemployment gaps to the variation in female labor force participation and female unemployment rates.

\subsection{Mechanisms}

We distinguish four mechanisms in which female labor force participation and gender unemployment gaps can be related. First, career breaks, such as family leaves, are detrimental to human capital accumulation and productivity. Job-protected family leaves decrease the mothers' post-leave earnings and employment (Albrecht et al. 1999; Beblo et al. 2009; Lalive and Zweimüller 2009) and therefore also increase the risk of subsequent unemployment. In addition, without job protection, family leaves are likely to be followed by spells of unemployment as women have to search for a job first when they return to the labor force (Johnson 1983). Finally, the presence of young children typically reduce productivity at work or the job search effort.

Second, the anticipation of substantial family-related career breaks may reduce the incentives of young women to invest in their human capital (Weiss and Gronau 1981). At the other side of the market, anticipation of long family-related job interruptions or the 
high risk of labor force withdrawal will reduce employers' incentives to hire young women (evidence surveyed in Darity and Mason (1998) and Blau et al. (2010)) or to offer them career paths and job training similar to those of men (Puhani and Sonderhof 2011). Again, lower labor force participation leads to higher risk of unemployment.

Third, frequent or long unemployment spells reduce the probability of finding a job, which makes a job search more costly and may discourage unemployed women, who have a relatively high reservation wage, from the labor force (Blundell et al. 1998). Note that this so-called discouraged worker effect establishes a link in the opposite direction, in which gender unemployment gaps in favor of men reduce the labor force participation of women relative to men.

Finally, there is what we call the compositional effect, which arises from the fact that the size of the female labor force directly enters the formula of the gender unemployment gap as the denominator in the definition of the female unemployment rate. It follows that gender-specific changes in labor force participation, unless accompanied by proportional changes in unemployment, will alter the gender unemployment gaps. While the previously listed mechanisms imply a negative correlation between female labor force participation behavior and gender unemployment gaps, the compositional effect can be in any direction, depending on the nature of the selection of women into the labor force. Selection arises when individuals who participate in the labor force systematically differ in the analyzed outcome, here risk of unemployment, from those who are out of the labor force. While positive selection into employment is well known in the gender wage gap literature (Hunt 2002; Jurajda and Harmgart 2007; Olivetti and Petrongolo 2008), the effect of selection on gender unemployment gaps has not so far received much attention in the literature. ${ }^{25}$

\subsection{Evidence}

We next consider the four effects listed above as the potential mechanisms that stand behind the documented unemployment and labor force participation profiles, as presented above. We start with the discussion of the compositional effect.

\subsubsection{Compositional effect}

At the second stage of family life, the one immediately following childbirth (Group 1), female labor force participation rates plummet and we observe sizeable gender unemployment gaps in favor of men across the whole EU. In all but seven countries, these gaps are driven by a rise in the female unemployment rate relative to the first stage of family life, which is typically accompanied by no change or fall in the share of unemployed among women. ${ }^{26}$ If women who take family leave withdraw predominantly from employment, only the denominator of the unemployment rate is affected, thus increasing the unemployment rate among women in the period immediately following the childbirth but leaving intact the share of unemployed at that period, which is exactly the pattern observed in the data.

These patterns fit the consequences of the compositional effect of labor force withdrawal under negative selection into the labor force, ${ }^{27}$ suggesting that women who take family leaves after childbirth have lower probability of unemployment (i.e., lower observed unemployment rate) than women who stay in the labor force at that stage. ${ }^{28}$ Based on the information about labor market status in the year preceding 
the survey, our data suggest that in 19 of the 21 countries, among women who are currently on maternity or parental leave, less than $2 \%$ who were in the labor force a year ago were unemployed. Focusing on cross-country differences, the deeper the drop in female labor force participation in Group 1, the greater the size of this compositional effect: the data reveal a negative correlation of -0.60 (statistically significant at the $3 \%$ confidence level) between the female participation rate and the gender unemployment gap but no correlation between the female participation rate and the gender gap in the share of the unemployed among women in Group 1.

\subsubsection{The effect of family leave on subsequent risk of unemployment}

As children grow older (Groups 2 and 3), in the temporary leave countries, women return to the labor force, which should ceteris paribus drive the female unemployment rate back to its initial level. Instead, the female unemployment rate declines only slightly, and the share of the unemployed among women rises, which implies that the average risk of unemployment among women who took family leave has increased. ${ }^{29}$ This is in line with the negative effect of family leave and the presence of children on the productivity and on the probability of returning to work.

The longer the family leave, the higher the subsequent risk of unemployment, implying a positive relationship between the duration of family leaves and gender differences in unemployment in Group 2. The actual duration of family leave is not observed in the data but can be imputed as the share of women who drop out of the labor force after childbirth and return at the following stage of family life times 5, which captures the 5-year age band of the youngest child. ${ }^{30}$ In Group 2, the correlation between the imputed actual family leave duration and gender unemployment gaps is 0.60 and between the actual family leave duration and the gender gap in the share of the unemployed is 0.67 , both statistically significant at the $2 \%$ significance level. ${ }^{31}$ Small or no gender unemployment gaps in temporary leave countries in Group 4 suggest that the effect of parental leaves on female unemployment gradually fades away.

\subsubsection{Anticipation, discrimination, and discouraged worker effect}

The share of women who ultimately remain out of the labor force, as reflected by Group 4 , turns out to be the most important factor for the cross-country variation in gender unemployment gaps in the permanent withdrawal countries. ${ }^{32}$ The weaker the ultimate attachment of women to the labor market, the greater the risk of unemployment at all stages of family life. ${ }^{33}$ The sizable gender unemployment gaps among young childless individuals in the four Mediterranean countries are likely to be driven by the anticipation effect and statistical discrimination as discussed in Section 4.1. The discouraged worker effect could explain the fact that stages with above-average female unemployment rates are followed by stages of stagnation or further decline in female labor force participation in all permanent withdrawal countries and may, indeed, explain at least part of the permanent withdrawal. Gender differences in unemployment at all stages of family life in the Mediterranean countries are also consistent with taste-based gender discrimination. Which of these effects dominate and which way the causality goes remain questions for future research. 
In contrast, as there are zero or negative gender unemployment gaps in favor of men at the first and last stages of family life in the temporary leave countries, we conclude that none of the abovementioned factors are likely to play a significant role for gender unemployment gaps there.

\section{Results and discussion}

\subsection{The key findings from data decompositions}

In the series of the data decompositions, we first asked to what extent the documented cross-country variation in gender unemployment gaps can be explained by the countryspecific differences in pre-market human capital between women and men and then focused on human capital accumulated at the labor market, in which child-bringing and child-rearing constitute the key differences across gender. While gender differences in pre-market human capital explain only $23 \%$ of the cross-country variation in gender unemployment gaps, children and female labor force participation after childbirth turn out to be the major determinants of the gender differences in unemployment across the countries of the EU. While gender unemployment gaps among individuals with children younger than 15 in the family exceed 2.5 p.p. in 16 out of the 21 countries, women and men without children in 18 of the countries are almost equally likely to be unemployed.

In order to better understand the impact of children on gender differences in unemployment, we next disaggregated the data by five stages of family life, defined by age, fertility, and the age of the youngest child. We observed that gender unemployment gaps are always the highest at the stage following childbirth, driven by a high unemployment rate among mothers of children between 0 and 4 . It turns out that the high female unemployment rate after childbirth is mechanically driven by the withdrawal of women from employment into family leave. We showed that the mechanical rise in unemployment at that stage results from the compositional effect of the size of the labor force on unemployment under negative selection into the labor force. It is only when women return from their family leaves that gender unemployment gaps, which are still substantial in size in a majority of the countries, reflect the true rise in female joblessness relative to that of men. In at least two thirds of the countries, gender unemployment gaps decrease with the age of the youngest child and disappear by the time no children younger than 15 are in the family.

We next focused on labor force participation profiles across the five stages of family life. We found that in most of the EU countries, gender labor force participation gaps open up only after women have children. Based on the participation profiles, we distinguish two types of countries: the temporary leave countries, where women take family leaves of various lengths after childbirth and then typically return again to the labor force, and the permanent withdrawal countries, where the shape of the participation profiles suggests that the majority of women who leave the labor force after childbirth never return. ${ }^{34}$ The eight permanent withdrawal countries include Ireland, the Benelux, and the Mediterranean countries except for France; the remaining 13 countries are the temporary leave countries. Finally, we noted that it is only in the four Mediterranean countries that substantial gender unemployment gaps in favor of men prevail at all stages of family life, including both the young childless individuals and the final stage of the family life. We interpret this as a signal of the overall disadvantaged position of women in the labor market there. 


\subsection{Cross-country variation in gender unemployment gaps}

We now introduce two factors that are closely related to the patterns documented above and that turn out to strongly correlate with the cross-country variation in the temporary leave and the permanent withdrawal countries, respectively: the statutory duration of paid family leave and the Eurobarometer measure of perceived prevalence of gender discrimination. ${ }^{35}$ We summarize our proposed explanation of cross-country differences in gender unemployment gaps based on these suggestive correlations within a simple regression framework.

We use gender unemployment gaps adjusted for gender differences in pre-market human capital and, as suggested by the data decompositions, focus separately on individuals with children below 15 and those without. We divide the sample into the temporary leave and permanent withdrawal countries and relate the pre-market human capitaladjusted gender unemployment gaps to the two factors, the statutory duration of paid family leave and the perceived gender discrimination, respectively.

Figure 8 shows that while the statutory duration of paid family leave explains $53.8 \%$ of the variation in gender unemployment gaps among individuals with children in the temporary leave countries, it has zero explanatory power for cross-country differences in gender unemployment gaps in the permanent withdrawal countries. On the other hand,

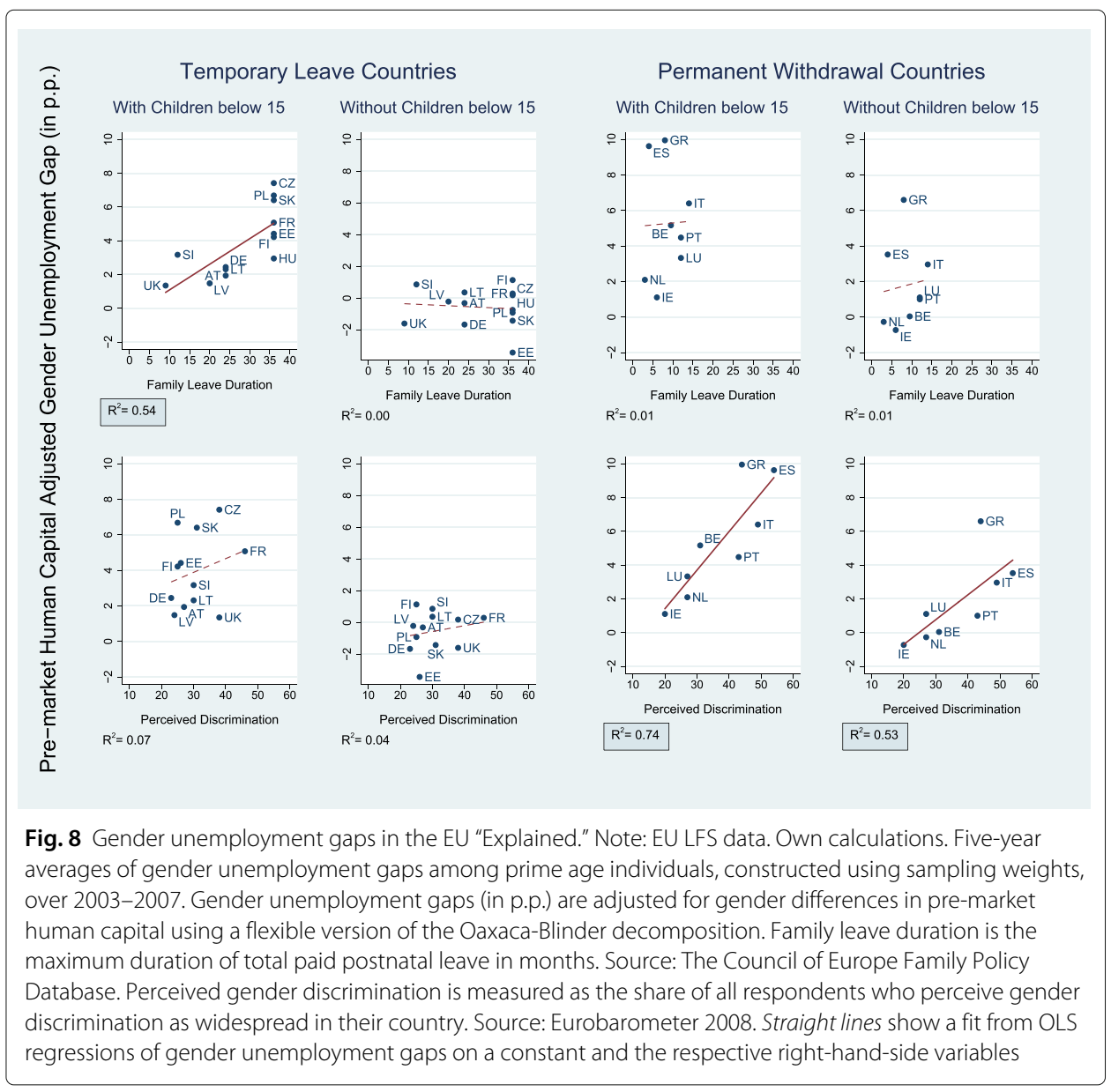


the perceived prevalence of gender discrimination is strongly positively correlated with gender unemployment gaps both among individuals with and without children younger than 15 in the permanent withdrawal countries $\left(R^{2}=0.74\right.$ and $\left.R^{2}=0.53\right)$ but is unrelated to the gender differences in unemployment among individuals in the temporary leave countries irrespective of the presence of children. ${ }^{36}$

When we combine all the steps of our proposed explanation into a single regression, using a sample of 40 gender unemployment gaps, i.e., two observations per country (among individuals with and without children below 15) with four explanatory variables plus a constant, the goodness of fit measures are $R^{2}=0.79$ and Adjusted $R^{2}=$ 0.77 respectively. ${ }^{37}$ The four explanatory variables are the following: a binary indicator whether the country belongs among the temporary leave countries, an interaction of the statutory duration of paid family leave with an indicator for individuals with children in the temporary leave countries, an interaction of perceived prevalence of gender discrimination with an indicator for individuals with children in the permanent withdrawal countries, and an interaction of perceived prevalence of gender discrimination and an indicator for individuals without children in the permanent withdrawal countries. $^{38}$

We therefore account for as much as $80 \%$ of the cross-country variation in gender unemployment gaps adjusted for gender differences in pre-market human capital by focusing separately on individuals with and without children, by dividing the sample into the two types of countries, and by applying a single explanatory factor, a different one in each group. ${ }^{39}$

While family leave duration and perceived gender discrimination may suffer from endogeneity, the very low explanatory power that each of the two factors has for the crosscountry variation in gender unemployment gaps in the other group of countries suggests that such endogeneity would have to be specific to a particular country type. Moreover, the division of countries into the two groups, based on the labor force participation of women, may be itself endogenous to the gender unemployment gaps we try to explain, even if female labor force participation is likely to have higher inertia than the gender unemployment gaps.

To overcome at least some of the limitations and to further support our proposed account of the cross-country variation, we estimate the relationship between gender unemployment gaps and paid family leave durations allowing for any time-invariant country-specific characteristics and country-invariant annual shocks, using macro-level panel data of $17 \mathrm{EU}$ countries over the 1990-2015 period. ${ }^{40}$ The regression of gender unemployment gap (in p.p.) on duration of paid family leave (in weeks)-with country and year fixed effects and the sample size of 402 country-year observations-yields a coefficient of paid family leave of 0.0159 with a standard error of $0.007 .{ }^{41}$ This coefficient (significant at the $5 \%$ level) implies that increasing the duration of paid family leave by 1 year ( 54 weeks) increases the gender unemployment gap by 0.865 p.p. While the country fixed effects among the permanent withdrawal countries range between 2.6 and 8.3 (with a median of 3.34), those in temporary leave countries range from -1.0 to 3.6 (with a median of 0.05). These fixed effects are likely to capture the more persistent country-specific factors, such as social norms and gender role attitudes, and correspond to the cross-sectional variation in the perceived prevalence of gender discrimination used in Fig. 8. 


\subsection{Institutions and social norms}

\subsubsection{Family leave}

Figure 9 reveals a close correspondence between the actual family leave duration, imputed from the data as defined earlier, and the statutory norm, suggesting a strong impact of the underlying institution on the observed participation behavior. ${ }^{42}$

Permanent withdrawal countries (indicated by a triangular marker) concentrate in the lower left corner-women there do not have an option of a temporary paid and jobprotected family-related career break and therefore tend to take either very short family leaves or to leave the labor force permanently. ${ }^{43}$ Algan and Cahuc (2006) find that in the Mediterranean countries, as well as in some countries of continental Europe including Belgium and the Netherlands, almost two thirds of respondents agree with the statement that "A preschool child suffers if the mother works," suggesting that the traditional perception of motherhood is widespread among the permanent withdrawal countries. Such perception of motherhood is likely to contribute to the absence of family leave policies supporting mothers' return to the labor force, as well as to the observed permanent labor force withdrawal.

\subsubsection{Prevalence of gender discrimination}

There are several ways of interpreting the Eurobarometer measure of the perceived prevalence of gender discrimination and its high correlation with gender unemployment gaps. First: Respondents have a better knowledge of individual productivity and cases of discrimination than a researcher, and the Eurobarometer measure suggests that gender unemployment gaps reflect "true" discrimination. Second: Respondents do not correctly condition on individual characteristics and productivity and therefore misclassify unequal treatment due to real gender differences in productivity as discrimination, in which case gender unemployment gaps as well as the perceived gender discrimination may still be a consequence of unobserved gender differences in human capital and productivity. Third: The respondents' answers are based on aggregate statistics such as gender unemployment

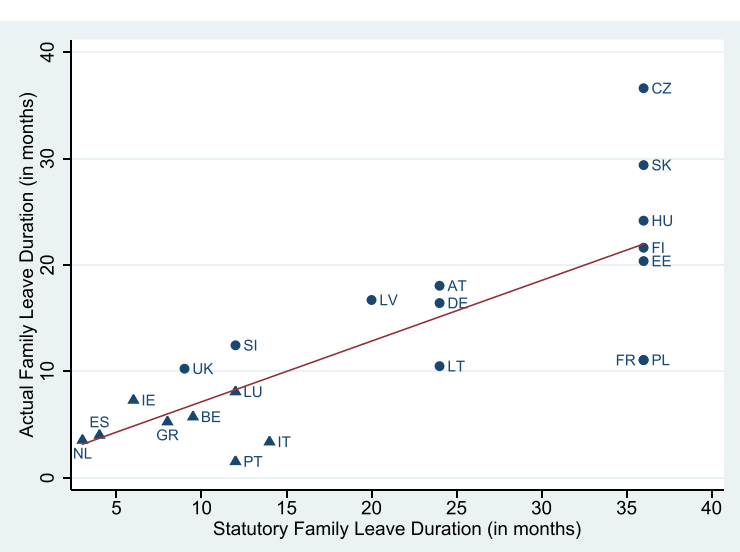

Fig. 9 Actual family leave duration and total paid family leave. Note: Actual leave is imputed from the EU LFS data as the difference between the 5-year averaged (over 2003-2007) female labor force participation rate in Group 2 and Group 1 times 60. Annual participation rates (of prime age individuals) are constructed using sampling weights. Statutory duration of paid family leave is the maximum duration of total paid postnatal leave in months from The Council of Europe Family Policy Database. Permanent withdrawal countries are marked by a triangle; temporary leave countries are marked by a circle 
gaps, suggesting a reversed causality between the gender differences in unemployment and the perceived prevalence of discrimination. The last case is unlikely, as it would imply a similar correlation also among the temporary leave countries, but there is none. This leaves us with gender discrimination and gender differences in unobserved human capital as the two candidate explanations. As nothing else can be revealed from our data about the latter, we focus on "true" gender discrimination as the interpretation of the Eurobarometer measure.

So far, we have considered only statistical discrimination, when weak labor force attachment of women from previous cohorts is interpreted by the employers as a signal of future labor force participation of the current cohort of young women. Gender differences in unemployment may also be a consequence of taste-based discrimination arising from gender stereotypes rooted in traditional family culture, associated by Algan and Cahuc (2007) with Catholicism or Greek Orthodoxy. With the exception of the Netherlands, the permanent withdrawal countries have the highest share of Catholics (or the Greek Orthodox in Greece) in the population in the EU. Fortin (2005) and AGM find a positive relationship between the prevalence of the belief that "when jobs are scarce, men should have more right to a job than women" and gender differences in labor market outcomes. Using a more recent measure of "prejudice," namely, the share of men that agree with the above statement in the European and World Values Surveys in 1999, we find that the correlation between prejudice and the perceived prevalence of gender discrimination among the permanent withdrawal countries is $0.52 .{ }^{44}$

Algan and Cahuc (2006) argue that traditional gender role attitudes may give rise to job protection policies that favor traditional full-time male employment but are detrimental for female employment. Kahn (2007) finds that employment protection laws increase the incidence of temporary employment among women, which is likely to increase their job insecurity. The left panel of Fig. 10 shows that the size of the gender gap in the share of permanent contracts is positively related to the perceived prevalence of gender discrimination in the permanent withdrawal countries. ${ }^{45}$ Finally, Petrongolo (2004) finds that women in Southern Europe are involuntarily overrepresented in fixed-term employment contracts, relative to men with the same productivity, and interprets her finding as indirect evidence of gender discrimination.

Flexible working conditions, on the other hand, help women combine work and family, allowing them to stay attached to the labor market and maintain their human capital when their children are young (Kahn 2007). The right panel of Fig. 10 shows an inverse relationship between the incidence of part-time jobs among women and the perceived prevalence of gender discrimination in the permanent withdrawal countries. While the share of part-time jobs among working prime age women exceeds $40 \%$ in Belgium and the Netherlands, it is below $25 \%$ in the four Mediterranean countries. ${ }^{46}$

\section{Conclusions}

The size of gender unemployment gaps varies substantially across countries of the European Union. We show that while gender differences in pre-market human capital have some explanatory power for the unemployment gaps, the observed variation is predominantly driven by the cross-country differences in female labor force participation after childbirth. We find that gender unemployment gaps exist only among individuals with children and result from the above-average female unemployment rates of mothers 


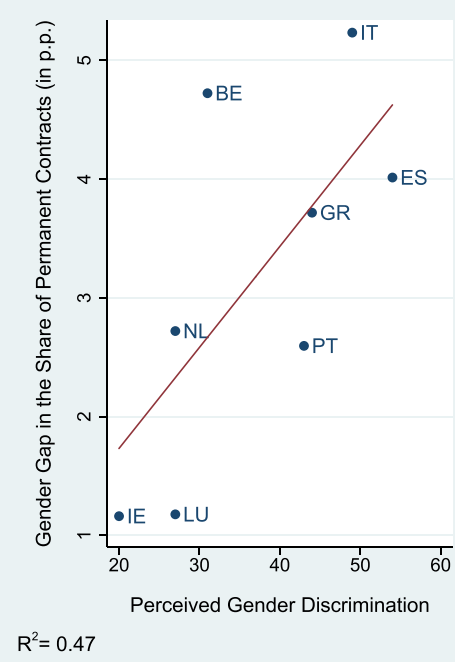

$R^{2}=0.47$

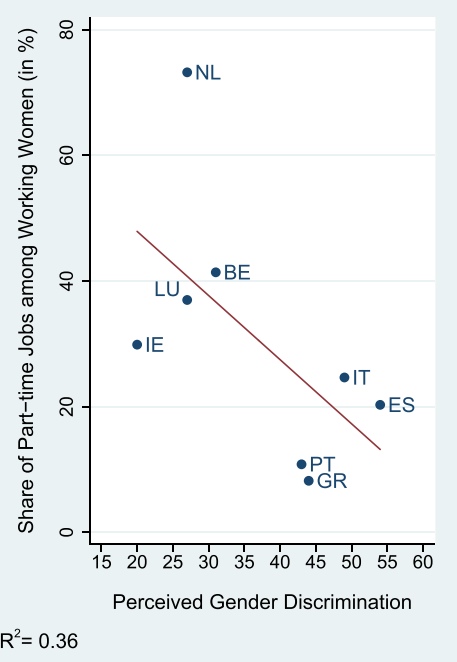

Fig. 10 Gender discrimination and employment contracts. Note: Perceived gender discrimination is a share of all respondents who perceive gender discrimination as widespread in their country (from the Eurobarometer survey in 2008). The $Y$-axis on the left panel shows the difference between the shares of permanent contracts (among all work contracts) of men and women (in p.p.). The $Y$-axis on the right panel shows the share of part-time jobs among women who work (in \%). Both measures are computed from annual EU LFS data for prime age individuals using sampling weights and averaged over 2003-2007

when compared to men or to women without children in the family. Female unemployment rates, in turn, are closely related to female labor force participation profiles across the five stages of family life. There is a sharp drop in female labor force participation after childbirth accompanied by a sharp rise in the female unemployment rate, but no change in the share of the unemployed in the female population. The corresponding rise in gender unemployment gaps after childbirth is driven purely by a compositional change in the labor force, when many women withdraw from employment into a family leave.

After family leave, when women return to the labor force, the share of the unemployed women rises again towards their unemployment rate. The higher risk of unemployment after family leave can be attributed to the negative impact of career interruption on human capital accumulation as well as to the direct transitions to unemployment when family leave is not job-protected.

Based on female labor force participation behavior across the five stages of family life, we distinguish two types of countries: 13 temporary leave countries, where the majority of women take family leaves of various lengths after childbirth and then return to the labor force, and 8 permanent withdrawal countries, where the shape of the participation profiles suggests that the majority of women who leave the labor force after childbirth never return.

Turning to the underlying institutions, we find that the length of the statutory paid family leave can "explain" almost half of the cross-country variation in gender unemployment gaps among the temporary leave countries. In contrast, the permanent withdrawal countries, where gender role attitudes rooted in traditional family culture are strong and widespread, have only very short or no paid family leaves. The perceived prevalence of gender discrimination varies substantially in permanent withdrawal countries and turns 
out to be strongly positively correlated with the size of gender unemployment gaps there. While the two unilateral relationships cannot be interpreted as causal, they are consistent with the main conclusions that follow from our data decompositions. We further support our account of the variation in gender unemployment gaps across the EU with a regression of gender unemployment gaps on the duration of paid family leave for 17 countries over the last 25 years, with country and year fixed effects. Based on this country-level analysis, extending the duration of paid family leave by 1 year leads to an increase in gender unemployment gap by 0.865 p.p.

The empirical facts presented in this paper imply that family policies and institutions affecting mothers' transition from leave to work and facilitating the family-work balance are more important policy instruments to tackle the gender differences in unemployment (in favor of men) than other active labor market policies targeted at women. In particular, (1) shorter paid (job-protected) family leave combined with institutional childcare availability; (2) support of flexible forms of work (such as part-time work, flexible working hours, or work from home); and (3) measures that help mitigate the consequences of leave-related skill depreciation (training or re-qualification programs designed for women returning to work after childbirth) are likely to reduce the high unemployment rates among mothers with children that, to a great extent, stand behind the observed gender unemployment gaps, at least in the temporary leave countries.

Future research is needed to test the proposed interpretations of the presented facts, as well as to explore which determinants make countries belong to the temporary leave or permanently withdrawal type. The findings summarized in this paper should serve as a starting point.

\section{Endnotes}

${ }^{1}$ While the latter paper explores predominantly the gender employment gaps, it also shows that unionization raises the female relative to the male unemployment rate.

${ }^{2}$ There is also Albanesi and Sahin (2013), who focus primarily on the USA but also include a short section on international evidence from 19 OECD countries (including a series of the West European countries). They suggest that convergence in the labor force participation of women and men played a key role in the reduction of gender unemployment gaps over time.

${ }^{3}$ We provide evidence about $21 \mathrm{EU}$ countries for the period of 2003-2007, compared with only 14 West European countries and the USA in the second half of the 1990s in AGM. As a collection of standardized national labor force surveys, the EU LFS data is superior to ECHP in terms of the sample size and representativeness. Section Replication of Azmat et al. 2006 in the Appendix provides information about our replication of the AGM results.

${ }^{4}$ AGM conjecture that this may be one of the reasons for the lack of research interest in gender unemployment gaps as the majority of the international research had been carried out on data from Anglo-Saxon countries.

${ }^{5}$ While gender unemployment gaps have decreased in some of the Benelux and Mediterranean countries, their ranking in the EU have remained stable over the last 10 years. See Fig. 13 in the Appendix.

${ }^{6}$ The correlation between the gender unemployment gaps in the $21 \mathrm{EU}$ countries in 2007 and 2013 is 0.85 ; the correlation between countries' respective ranks when ordered 
by the size of the gap is 0.79 . The absolute value of the change in the rank in 16 of the 21 countries is at most 4; the average absolute value of the change in the rank was 3.2.

${ }^{7}$ The exact source of the data, the definition of the sample, and the data description is in Section EU LFS data in the Appendix.

${ }^{8}$ The correlation between gender unemployment gaps (averaged over 2003-2007) among prime age individuals and among all individuals in the population in the 21 countries is 0.98 , suggesting that our main conclusions should be robust to the choice of the sample.

${ }^{9}$ As the data only permit us to construct participation profiles from cross-sectional data, the observed permanent withdrawal could be also driven by inter-cohort changes, namely, by the increase in female labor force participation. A simple version of a cohort analysis in Appendix Cohort analysis shows that while the profiles shift upward over time, their shape remains the same across cohorts.

${ }^{10}$ A term coined by Altonji and Blank (1999).

${ }^{11}$ We use standard but rather limited measures of human capital. The lack of more detailed information in the data is a cost of using a rich dataset in terms of the number of countries and the size and representativeness of the samples.

${ }^{12}$ In other words, when comparing individuals, we condition on what is known as the potential work experience. This approach also allows us to control for potential cohort differences in the quality of education, which is likely to be important, in particular in the New-EU member states, where the analyzed workforce still contains those educated under the Communist regime and those educated after the transition to the market economy.

${ }^{13}$ This is the most detailed categorization we can achieve given the information available in the data and given the need to ensure that each cell is sufficiently populated.

${ }^{14}$ In Germany, the two gaps are not statistically significantly different from zero.

${ }^{15}$ The coefficient of variation of the pre-market human capital-adjusted gender unemployment gaps is 1 , compared to the corresponding measure of 1.3 for the unadjusted gaps.

${ }^{16}$ We cannot distinguish between individuals who never had children and those whose children have already grown up. There are certainly both ex ante (Group 0 ) and ex post (Group 4) differences between career paths of individuals who plan to have children and those who do not, which we are forced to ignore and to interpret the results for the two endpoints of family life as averaged over the two types of individuals.

${ }^{17}$ The almost zero gender differences in unemployment in these two groups may underestimate the gender unemployment gaps among the individuals who plan to have children and among those whose children are grown up, as they are combined with individuals who do not plan to have children (Group 0) and with individuals who never had children (Group 4), respectively. This would, however, require substantial gender unemployment gaps in favor of women among truly childless individuals (who form less than one third of the sample, according to demographic trends), which is unlikely.

${ }^{18}$ Some countries such as Greece or Italy, however, struggle with high unemployment rates among the young (Group 0), irrespective of gender, which somewhat alters the typical shape of the female and male unemployment profiles.

${ }^{19}$ The fact that men with families have better labor market outcomes than the ones without is well established. Previous research has focused primarily on the question 
whether this so-called family gap is driven by a selection of above-average-productivity men to marry or by the fact that family increases men's effort at work and reduces their reservation wage (see, for example, Korenman and Neumark (1991); Ginther and Zavodny (2001)).

${ }^{20}$ Unemployment rate is defined as the ratio of the number of the unemployed divided by the number of individuals in the labor force.

${ }^{21}$ Consistent with the "family gap" phenomenon mentioned earlier, male labor force participation is always the highest in families with young children.

${ }^{22}$ Formally, $\frac{\left(\mathrm{FLFP}_{3}-\mathrm{FLFP}_{1}\right)}{\left(\mathrm{FLFP}_{0}-\mathrm{FLFP}_{1}\right)}<0.50$, where $\mathrm{FLFP}_{j}$ is the female labor force participation in group $j$.

${ }^{23}$ Aggregate development in female and male labor force participation rates between 2000 and 2007 are depicted in Fig. 14 in the Appendix.

${ }^{24}$ See Section Cohort analysis in the Appendix. Moreover, note that the inter-cohort changes also affect gender unemployment gaps as the behavior of the previous cohorts of women form a basis for the anticipated future labor force participation behavior of the current cohorts of young women, thus affecting both individual decisions and employers' incentives to statistically discriminate against young women.

${ }^{25}$ AGM mention only in a footnote the possibility of a positive selection effect on gender unemployment gaps as an analogy to the gender wage gap case emphasized in Olivetti and Petrongolo (2008). Bicakova (2014) formalizes the effect of selection on gender unemployment gaps and derives the corresponding Manski bounds.

${ }^{26}$ These seven countries suffer from a high unemployment of youth, which is followed by a decline in both female and male measures of unemployment between the first two stages of family life. The two female unemployment measures, however, diverge from each other and from those of men in a similar way as in the rest of the sample.

${ }^{27}$ The compositional effect describes the mechanical relationship between the size of the labor force and unemployment, given by the fact that unemployment rate is defined as a ratio of the unemployed and those in the labor force. See Bicakova (2014) for details.

${ }^{28}$ This is not surprising, as only previously employed women (in contrast with their unemployed counterparts) meet the conditions for enjoying the benefits of a statutory family leave, both in terms of pay and job security.

${ }^{29}$ A pattern analogous to the temporary leave participation profiles at the third stage of family life (Group 2) can be detected also among those permanent withdrawal countries, where some women come back to the labor force after their family leaves, but it is almost negligible.

${ }^{30}$ The exact formula for the imputed length of the actual leave is the difference between the female labor force participation rates in Group 2 and Group 1 times 5 (times 60 when expressed in months).

${ }^{31}$ Note that the compositional effect of the increase in the female labor force at the third stage of family life still corresponds to the case of negative selection as the increased average risk of unemployment of women returning to the labor force is still between zero and the unemployment rate among women who have stayed in the labor force. The change in the labor force due to the return of women from family leaves therefore increases the share of the unemployed among women but reduces the female unemployment rate.

${ }^{32}$ Note that this rate is below $65 \%$ in all the Mediterranean permanent withdrawal countries except for Portugal, where a relatively high female participation rate is a consequence 
of a series of external shocks after WW2: colonial war, male emigration in the 1960s, and the 1976 revolution.

${ }^{33}$ The correlation between female participation rates and gender unemployment gaps in Group 4 is -0.66 and the correlation between female participation rates in Group 4 and the aggregate gender unemployment gaps is -0.64 , both statistically significant at the $10 \%$ significance level.

${ }^{34}$ As the data only permit us to construct participation profiles from cross-sectional data, the observed permanent withdrawal could be also driven by inter-cohort changes, namely, by the increase in female labor force participation. A simple version of a cohort analysis in the Appendix Cohort analysis shows that while the profiles shift upward over time, their shape remains the same across cohorts.

${ }^{35}$ See Sections Duration of the statutory family leaves and Discrimination and prejudice measures in the Appendix for the exact definitions and sources.

${ }^{36}$ Note that we do not propose any explanatory factor for the variation in gender unemployment gaps among individuals without children younger than 15 in the temporary leave countries as there are almost no gaps in favor of men and not much variation to explain.

${ }^{37}$ The gender discrimination indicator is missing for Hungary, leaving 40 data points for 20 countries.

${ }^{38}$ Regression with full interactions among the two binary indicators (for the type of country and for the presence of children) and with the two explanatory factors (statutory duration of paid family leave and the perceived prevalence of gender discrimination) renders Adjusted $R^{2}=0.75$. Statistically insignificant variables are dropped in the preferred specification in the text.

${ }^{39}$ Results for the unadjusted gaps are fairly similar: Identical specification explains $68 \%$ of the variation in unadjusted gender unemployment gaps. See Fig. 12 in the Appendix.

${ }^{40}$ The gender unemployment gaps for individuals $25-54$ years old were calculated from unemployment rates of 25-54 year olds with any level of education, extracted from Eurostat website http://ec.europa.eu/eurostat/web/lfs/data/database on November 14, 2016, as part of the series "Unemployment rates by sex, age and educational attainment level (\%)." The longest possible duration of statutory paid family leave (in weeks) available to mothers in a given country in a given year was extracted from the OECD Family Database Indicators web site at http://www.oecd.org/els/family/database.htm on November 14, 2016, as part of the xls file "PF2.5 Trends in leave entitlements around childbirth." Due to missing values, the data is an unbalanced panel of $17 \mathrm{EU}$ countries (Austria, Belgium, Czech Republic, Denmark, Finland, Greece, Hungary, Ireland, Italy, Luxembourg, Netherlands, Norway, Poland, Portugal, Spain, Sweden, UK) for which more than 2 years of data are available over the period 1990-2015, with 402 country-year observations in total.

${ }^{41}$ The full regression output is available from the author upon request.

${ }^{42}$ The $R^{2}$ from a regression of the actual family leave duration on a constant and the duration of the statutory paid family leave of 0.60 .

${ }^{43}$ The actual family leaves in permanent withdrawal countries are short by construction as only very few women who leave the labor force after childbirth in Group 1 come back in Group 2.

${ }^{44}$ See the Appendix for the additional data source and the exact definition of prejudice. 
${ }^{45}$ Note that gender differences in the incidence of permanent contracts among working prime age individuals exceed 3.5 p.p. in three of the Mediterranean countries as well as in Belgium.

${ }^{46}$ It is interesting that the overrepresentation of women in the small share of part-time jobs that exist in Southern Europe is also involuntary in contrast to the other EU countries (Petrongolo 2004). In contrast with countries like the Netherlands where the widespread use of part-time jobs helps women combine work and family, the scarce part-time jobs in the Mediterranean countries seem to serve employers as tools for gender discrimination.

${ }^{47}$ The exact reference is as follows: European Commission, Eurostat, the 2008 release of the anonymized European Union Labor Force Survey datasets for the reference years 2001-2007. We use the Spring data (from Quarter 2) only to ensure comparability across years. The Eurostat has no responsibility for the results and conclusions presented in this paper.

${ }^{48}$ Children cannot be linked to their parents for all the countries and years in the data, but the presence of individuals younger than 15 years old in the typical family with only one or two prime age household members makes parenthood very likely. Note that information about children and their age is incomplete or missing in Ireland in the years 2003-2005 and in Italy for 2004. Whenever we disaggregate the data by the five stages of family life, these country-years are omitted from the analysis.

${ }^{49}$ The statutory length as well as actual duration and occurrence of family leaves taken by fathers is negligible relative to the career breaks taken by women and has little relevance for the present analysis.

${ }^{50}$ Namely, there are three cases in which we deviate from Figure 13 of The Council of Europe Family Policy Database: First, we take the duration of 36 months instead of 24 in France and Poland, where the earlier is for the second and subsequent child. Note also that the paid family leave in Poland is means-tested. Second, we take the duration of 24 months in Germany instead of 12 as the 12-month paid parental leave there can be increased to 24 months with proportional reduction of the amount paid.

\section{Appendix}

Data sources and sample size

\section{EU LFS data}

The data comprises 21 national labor force surveys conducted by the national statistical institutes across Europe and centrally processed by Eurostat into the European Union Labor Force Survey Data. ${ }^{47}$ We focus on prime age individuals (between 25 and 54 years old) with the sample size for respective country-years provided in Table 1.

Substantial changes in the sample size in some of the countries are driven by a change in the underlying national labor force survey included as part of the EU LFS data. To avoid any potential discontinuities and to smooth any business-cycle effects, the main analysis is based on 5-year averages from years 2003-2007 for the whole sample, except for the averages for years 2004-2007 in Austria and years 2006-2007 in Finland. ${ }^{48}$

\section{Duration of the statutory family leaves}

The maximum duration of paid family leave (including both maternity and parental leave), after which women can return to their jobs, comes from The Council of Europe Family Policy Database, Figure 13 in Part 3.3. ${ }^{49}$ For countries where the length of the statutory 
Table 1 Sample size

\begin{tabular}{|c|c|c|c|c|c|c|c|}
\hline Country & 2001 & 2002 & 2003 & 2004 & 2005 & 2006 & 2007 \\
\hline Austria & 25,217 & 24,770 & 23,539 & 19,338 & 21,933 & 21,526 & 21,848 \\
\hline Belgium & 10,333 & 11,770 & 11,549 & 12,289 & 12,172 & 12,148 & 11,637 \\
\hline Czech Republic & 24,919 & 26,254 & 25,678 & 26,265 & 25,929 & 25,915 & 25,639 \\
\hline Estonia & 2097 & 1979 & 1942 & 1823 & 1777 & 2035 & 2405 \\
\hline Finland & 17,410 & 17,217 & 16,670 & 16,032 & 15,628 & 14,967 & 14,739 \\
\hline France & 74,362 & 72,526 & 35,522 & 35,340 & 34,866 & 33,239 & 34,812 \\
\hline Germany & & 138,646 & 139,676 & 137,609 & 71,044 & 6747 & 4175 \\
\hline Greece & 32,404 & 31,049 & 29,244 & 33,202 & 32,243 & 30,954 & 29,745 \\
\hline Hungary & 34,500 & 34,003 & 36,993 & 34,517 & 32,109 & 31,727 & 31,333 \\
\hline Ireland & 42,766 & 43,372 & 41,651 & 35,395 & 37,441 & 35,381 & 34,905 \\
\hline Italy & 84,716 & 83,354 & 81,599 & 71,373 & 72,972 & 70,056 & 68,244 \\
\hline Latvia & 7535 & 2461 & 2445 & 2504 & 2310 & 1918 & 3565 \\
\hline Lithuania & 3899 & 5404 & 5043 & 5085 & 4991 & 4566 & 7148 \\
\hline Luxembourg & 6439 & 5715 & 7089 & 9194 & 9765 & 9373 & 2206 \\
\hline Netherlands & 44,642 & 47,773 & 46,826 & 54,695 & 55,073 & 56,644 & 51,300 \\
\hline Poland & 24,195 & 24,421 & 24,464 & 24,075 & 23,066 & 22,208 & 21,023 \\
\hline Portugal & 17,528 & 17,507 & 18,265 & 20,772 & 19,386 & 17,825 & 16,903 \\
\hline Slovakia & 12,867 & 12,190 & 12,274 & 12,058 & 12,122 & 11,897 & 11,409 \\
\hline Slovenia & 8976 & 9074 & 9255 & 8658 & 8139 & 7830 & 7642 \\
\hline Spain & 72,175 & 72,307 & 73,771 & 74,186 & 65,892 & 69,103 & 71,495 \\
\hline United Kingdom & 56,294 & 56,168 & 53,074 & 50,490 & 49,589 & 48,318 & 47,712 \\
\hline
\end{tabular}

Note: EU LFS, prime age individuals (25-54 year olds), conscripts excluded

paid family leave varies, we always take the longest possible paid family leave duration. The actual family leave duration imputed from the data confirms our choice of the measure of the duration of statutory family leave..$^{50}$

\section{Discrimination and prejudice measures}

Perceived gender discrimination comes from the Eurobarometer survey in 2008 and is measured as the share of all respondents who perceive gender discrimination as widespread in their country. We measure prejudice against women by the share of men that agree with the statement that when jobs are scarce, men should have more right to a job than women, as measured by the 1999 European and World Values Survey.

\section{Cohort analysis}

The profiles we present in the text match individuals either by age group or by a duration from the last childbirth. Cohort profiles are in many respects superior to age-based profiles when we discuss individual behavior, in particular among the permanent withdrawal countries, where female participation has been rising over the studied period and could lead to the observed permanent withdrawal pattern across cohorts. Unfortunately, pseudo-panel data at the cohort level cannot be constructed from 5 years of data, where age information is available only in 5-year age bands. However, the timing of childbirth provides us with the necessary variation in the data that enables us-at least to some extent-to explore the role of cohort effects in our analysis: Fig. 11 presents the labor force participation profiles of women from the same age group (a 5-year band between 2003 and 2007) over the five stages of family life. Clearly, for some "cohorts," the first and the last stages of family life cannot be populated, as it is defined by age. It is, however, 


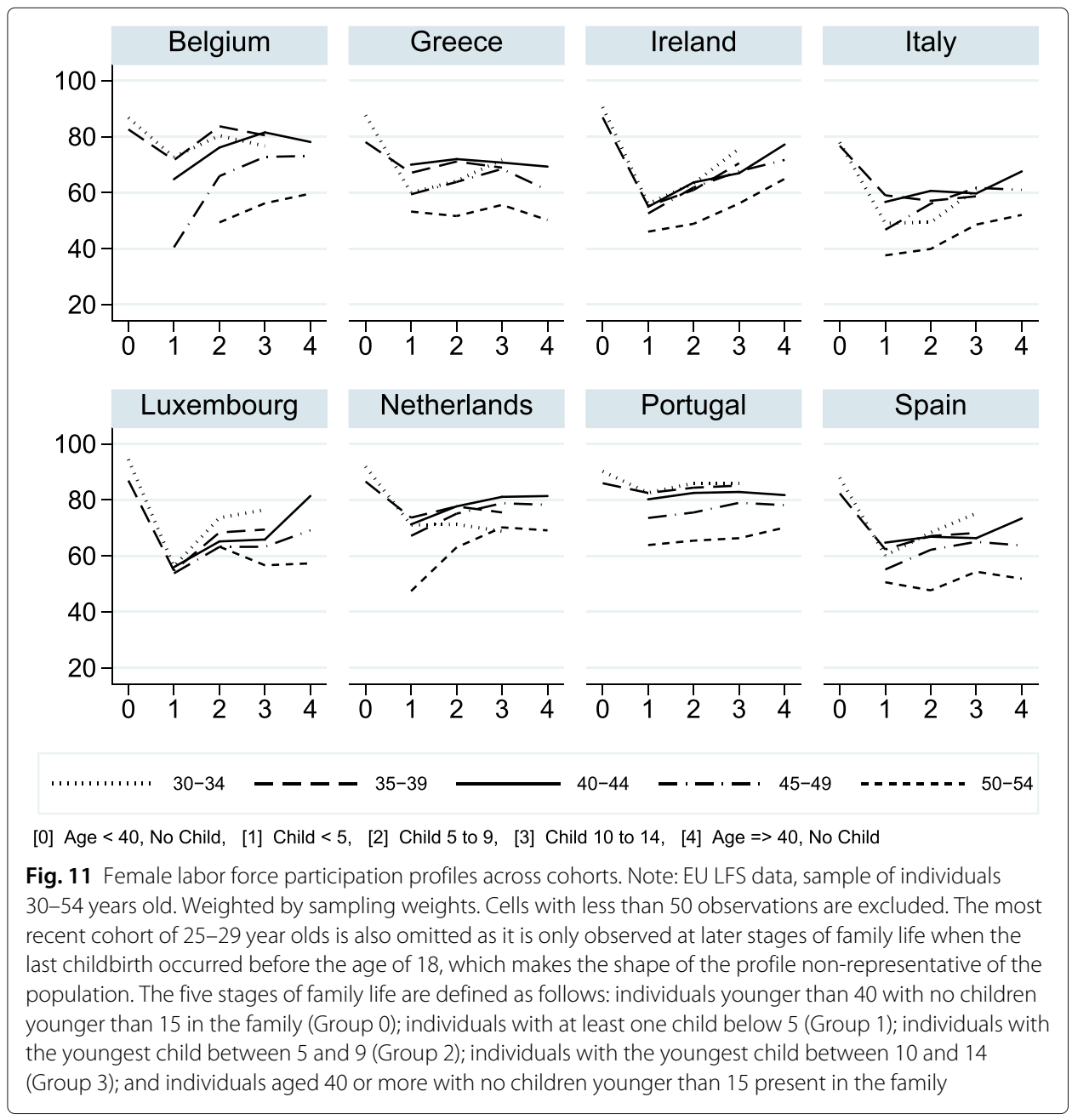

the evolution across the three stages defined by the age of the last child which is the most important for our argument and which shows that rising female participation among the permanent withdrawal countries has been shifting the profiles upwards while their shape remained relatively stable.

\section{Replication of Azmat et al. 2006}

Based on a series of country-level probit models of the probability to be unemployed as a function of standard individual characteristics, AGM conclude that gender differences in human capital accumulation are the main factor that leads to gender unemployment gaps. While we were able to qualitatively replicate the results from probit models estimated by AGM using our data, we decided to omit their voluminous regression output, as it did not bring substantively more insight on top of what we present and the length of the paper would double. A previous version of this paper also contained an analysis of transitions between labor market states in two subsequent years, similar to the one carried out in AGM. For the sake of comparison, we only mention here the main findings, which support-but are not crucial for-our main results: Similar to AGM, we find that gender differences in the flows between employment and unemployment are responsible for the 


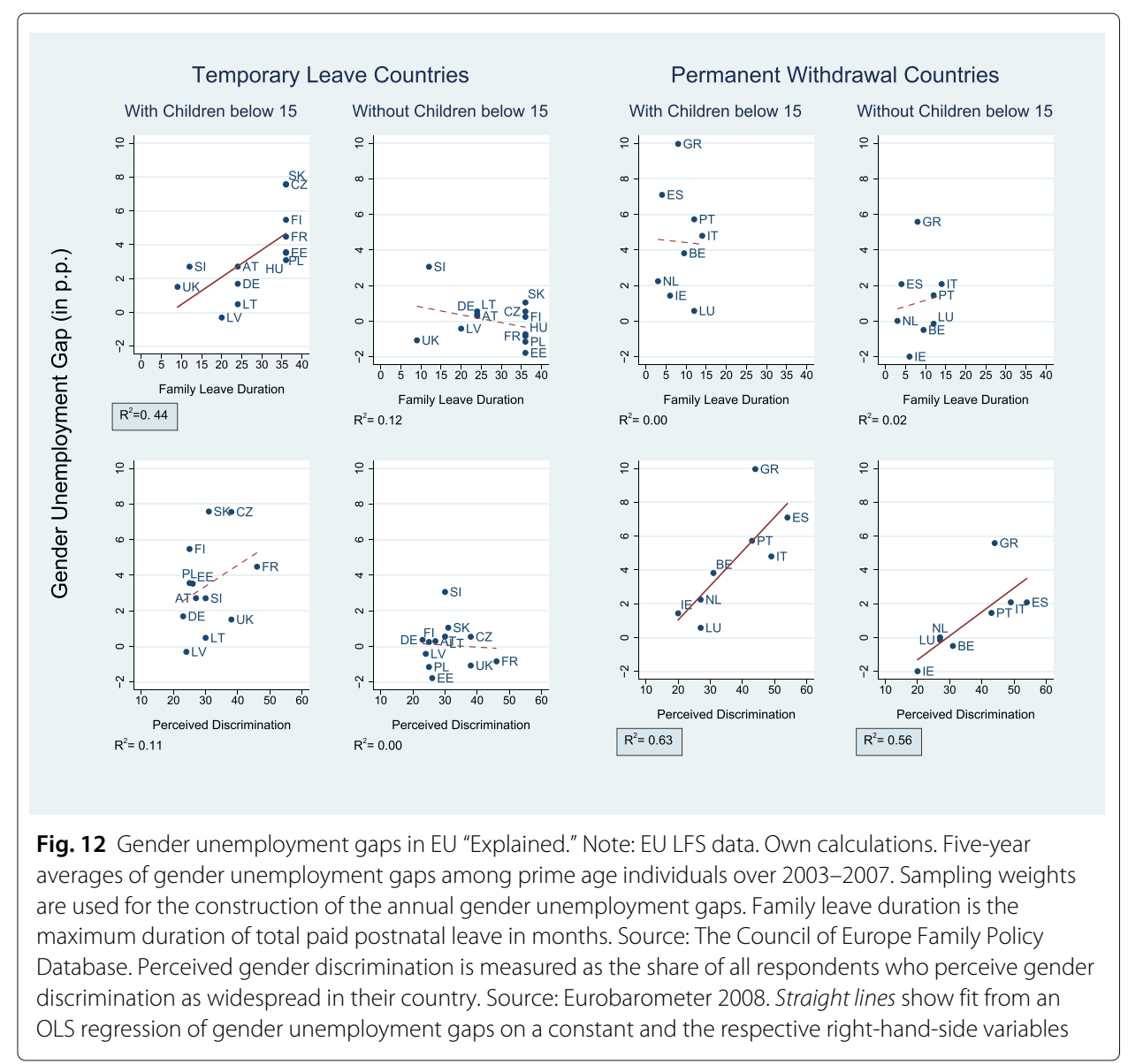

gender unemployment gaps at all stages of family life in the permanent withdrawal countries and among individuals with young children among the temporary leave countries. In contrast to AGM, who conclude that transitions into and out of the labor force do not contribute to gender unemployment gaps, two of the flows between unemployment and inactivity turn out to be important in our data: First, a high share of women moves directly from family leave into unemployment, and second, in some of the permanent withdrawal countries, women move from unemployment into inactivity substantially more often than men. 


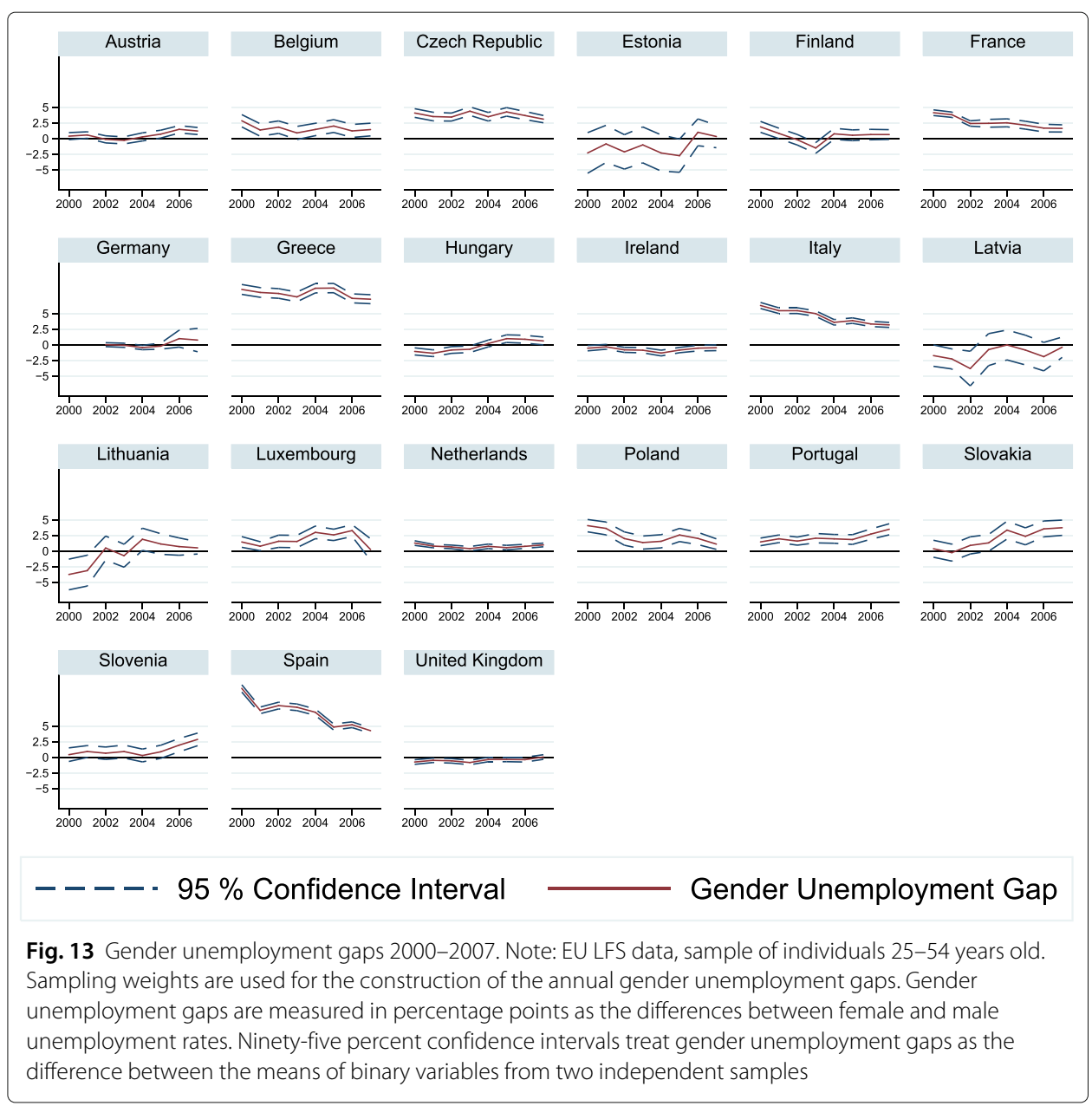




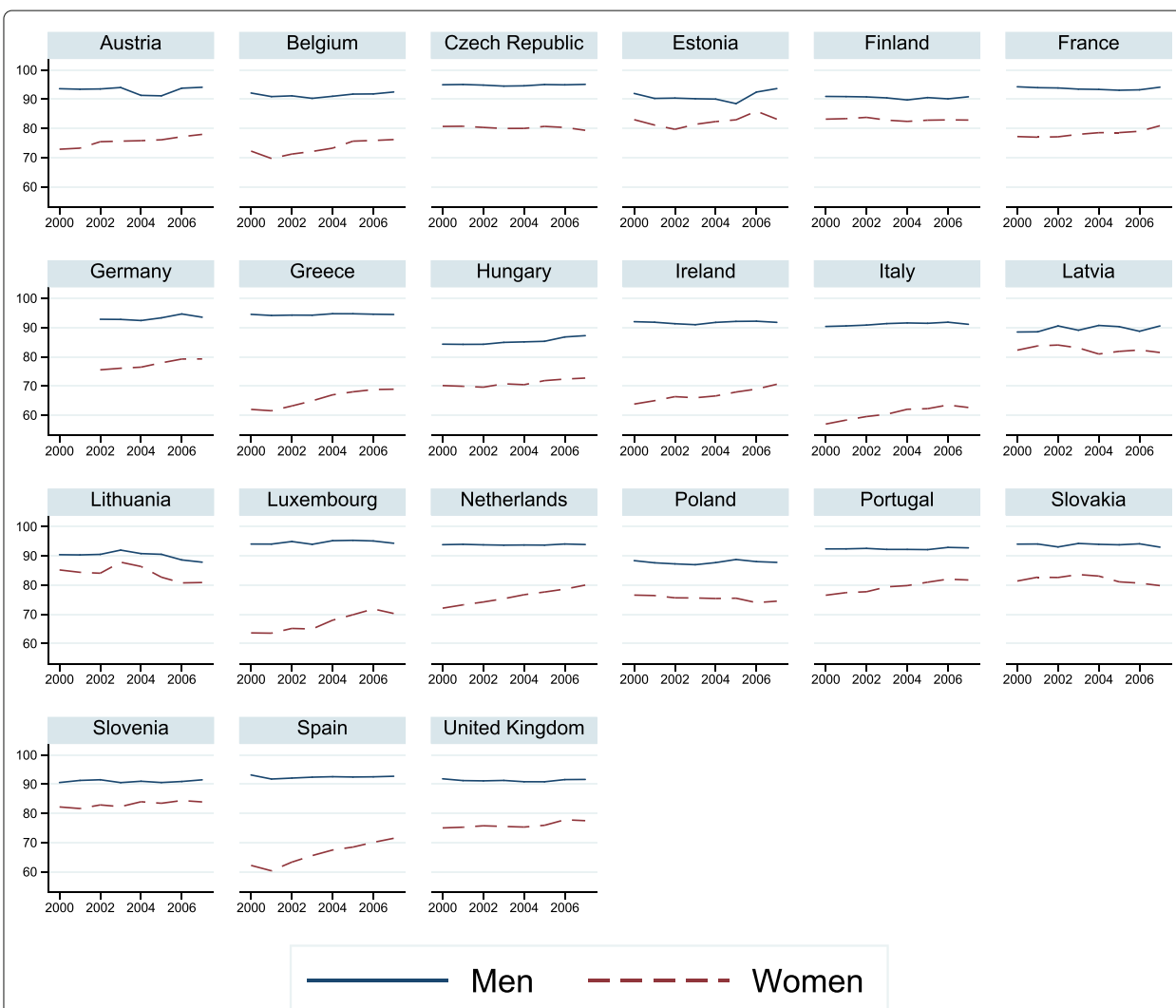

Fig. 14 Labor force participation rates by gender 2000-2007. Note: EU LFS data, sample of individuals 25-54 years old. Sampling weights are used for the construction of the annual participation rates. The share of the sum of employed and unemployed in the population

\section{Acknowledgements}

I would like to thank the anonymous referee and the editor for the useful remarks. The author thanks Štěpán Jurajda and Randy Filer for valuable comments. All errors remaining in this text are the responsibility of the author. Responsible editor: Martin Kahanec

\section{Funding}

This project was financially supported by grant number P402/12/G130 from the Grant Agency of the Czech Republic

\section{Competing interests}

The IZA Journal of European Labor Studies is committed to the IZA Guiding Principles of Research Integrity. The author declares that she has observed these principles.

Received: 15 September 2016 Accepted: 27 November 2016

Published online: 28 December 2016

\section{References}

Albanesi S, Sahin A (2013) The gender unemployment gap. CEPR discussion papers 9448, C.E.P.R. Discussion Papers. http://cepr.org/active/publications/discussion_papers/dp.php?dpno=9448

Albrecht JW, Edin PA, Sundström M, Vroman SB (1999) Career interruptions and subsequent earnings: a reexamination using Swedish data. J Hum Res 34(2):294-311

Algan Y, Cahuc P (2007) The roots of low European employment: family culture? In: NBER International Seminar on Macroeconomics. NBER Chapters. National Bureau of Economic Research, Inc. p 2005. https://ideas.repec.org/h/nbr/ nberch/0342.html

Algan Y, Cahuc P (2006) Job protection: the macho hypothesis. Oxf Rev Econ Policy 22(3):390-410

Altonji JG, Blank RM (1999) Race and gender in the labor market. Chapter 48 of Handbook of Labor Economics (Ashenfelter O, Card D, eds.), Vol. 3, 1, 3143-3259. Elsevier. http://econpapers.repec.org/bookchap/eeelabchp/3-48.htm Azmat G, Güell M, Manning A (2006) Gender gaps in unemployment rates in OECD countries. J Labor Econ 24(1):1-38 Beblo M, Bender S, Wolf E (2009) Establishment-level wage effects of entering motherhood. Oxf Econ Papers 61:i1 1 —i34 Becker GS (1985) Human capital, effort, and the sexual division of labor. J Labor Econ 3(1):S33—58

Bertola G, Blau F, Kahn L (2007) Labor market institutions and demographic employment patterns. J Popul Econ 20(4):833-867 
Bicakova A (2014) Selection into labor force and gender unemployment gaps. CERGE-El working papers wp513. The Center for Economic Research and Graduate Education - Economic Institute, Prague

Blau F, Ferber M, Winkler A (2010) The economics of women, men, and work. 6. Prentice-Hall. https://www. pearsonhighered.com/program/Blau-Economics-of-Women-Men-and-Work-The-7th-Edition/PGM275456.html

Blau FD, Kahn LM (2003) Understanding international differences in the gender pay gap. J Labor Econ 21(1):106-144

Blundell R, Ham J, Meghir C (1998) Unemployment, discouraged workers and female labour supply. Res Econ 52(2):103-131

Darity W, Mason P (1998) Evidence on discrimination in employment: codes of color, codes of gender. J Econ Perspect 12(2):63-90

Fortin NM (2005) Gender Role Attitudes and the labour-market outcomes of women across OECD countries. Oxf Rev Econ Policy 21(3):416-438

Ginther DK, Zavodny M (2001) Is the male marriage premium due to selection? The effect of shotgun weddings on the return to marriage. J Popul Econ 14(2):313-328

Hoynes H, Miller DL, Schaller J (2012) Who Suffers during Recessions? J Econ Perspect 26(3):27-48. https://ideas.repec. org/a/aea/jecper/v26y2012i3p27-48.html

Hunt J (2002) The transition in East Germany: when is a ten-point fall in the gender wage gap bad news J Labor Econ 20(1):148-169

ILO (2016) Women at Work: Trends 2016. International Labour Organization (ILO)

Johnson JL (1983) Sex differentials in unemployment rates: a case for no concern. J Pol Econ 91 (2):293-303

Jurajda S, Harmgart H (2007) When do female occupations pay more J Comp Econ 35(1):170-187

Kahn LM (2007) The impact of employment protection mandates on demographic temporary employment patterns: international microeconomic evidence. Econ J 117(521):333-356

Korenman S, Neumark D (1991) Does marriage really make men more productive? J Hum Res 26(2):282-307

Lalive R, Zweimüller J (2009) How does parental leave affect fertility and return to work? Evidence from two natural experiments. Q J Econ 124(3):1363-1402

Mincer J (1993) Education and unemployment. Chapter 7 of Studies in Human Capital (Mincer J, ed.), Vol. 1, 1, 212-238. Edward Elgar. https://www.e-elgar.com/shop/studies-in-human-capital?__website=uk_warehouse

Nopo H (2008) Matching as a tool to decompose wage gaps. Rev Econ Stat 90(2):290-299

OECD (2002) Employment outlook 2002. https://www.oecd.org/els/emp/oecdemploymentoutlook2002.htm

OECD (2008) Employment outlook 2008. http://www.oecd.org/els/emp/oecdemploymentoutlook2008.htm

Olivetti C, Petrongolo B (2008) Unequal pay or unequal employment? A cross-country analysis of gender gaps. J Labor Econ 26(4):621-654

Petrongolo B (2004) Gender segregation in employment contracts. J Eur Econ Assoc 2(2-3):331-345

Puhani P, Sonderhof K (2011) The effects of parental leave extension on training for young women. J Popul Econ 24(2):731-760

Weichselbaumer D, Winter-Ebmer R (2005) A meta-analysis of the international gender wage gap. J Econ Surv 19(3):479-511

Weichselbaumer D, Winter-Ebmer R (2007) The Effects of Competition and Equal Treatment Laws on Gender Wage Differentials. Econ Policy 22:235-287

Weiss Y, Gronau R (1981) Expected interruptions in labour force participation and sex-related differences in earnings growth. Rev Econ Studies 48(4):607-19

\section{Submit your manuscript to a SpringerOpen ${ }^{\circ}$ journal and benefit from:}

$\checkmark$ Convenient online submission

- Rigorous peer review

- Immediate publication on acceptance

- Open access: articles freely available online

- High visibility within the field

Retaining the copyright to your article

Submit your next manuscript at $\gg$ springeropen.com 